\title{
Selective Cortical Layering Abnormalities and Behavioral Deficits in Cortex-Specific Pax6 Knock-Out Mice
}

\author{
Tran Cong Tuoc, ${ }^{1,2 \star}$ Konstantin Radyushkin, ${ }^{1 \star}$ Anton B. Tonchev, ${ }^{3}$ Maria Carmen Piñon, ${ }^{4}$ Ruth Ashery-Padan, ${ }^{5}$ \\ Zoltán Molnár, ${ }^{4}$ Michail S. Davidoff, ${ }^{6}$ and Anastassia Stoykova ${ }^{1,2}$ \\ ${ }^{1}$ Department of Molecular Cell Biology, Max Planck Institute for Biophysical Chemistry, 37077 Göttingen, Germany, ${ }^{2}$ Center of Molecular Physiology of the \\ Brain, Deutsche Forschungsgemeinschaft, 37073 Göttingen, Germany, ${ }^{3}$ Laboratory of Cell Biology, Faculty of Pharmacy, Medical University, 9002 Varna, \\ Bulgaria, ${ }^{4}$ Department of Physiology, Anatomy and Genetics, University of Oxford, Oxford OX1 3QX, United Kingdom, ${ }^{5}$ Department of Human Molecular \\ Genetics and Biochemistry, Sackler Faculty of Medicine, Tel Aviv University, Tel Aviv 69978, Israel, and 'Department of Anatomy, University Medical \\ Center Hamburg-Eppendorf, University of Hamburg, 20246 Hamburg, Germany
}

The transcription factor Pax6 has been implicated in neocortical neurogenesis in vertebrates, including humans. Analyses of the role of Pax6 in layer formation and cognitive abilities have been hampered by perinatal lethality of Pax6 mutants. Here, we generated viable mutants exhibiting timed, restricted inactivation of Pax6 during early and late cortical neurogenesis using Emx1-Cre and hGFAP-Cre lines, respectively. The disruption of Pax6 at the onset of neurogenesis using Emx1-Cre line resulted in premature cell cycle exit of early progenitors, increase of early born neuronal subsets located in the marginal zone and lower layers, and a nearly complete absence of upper layer neurons, especially in the rostral cortex. Furthermore, progenitors, which accumulated in the enlarged germinal neuroepithelium at the pallial/subpallial border in the Pax6 mutants, produced an excess of oligodendrocytes. The inactivation of Pax6 after generation of the lower neuronal layers using $h G F A P$-Cre line did not affect specification or numbers of late-born neurons, indicating that the severe reduction of upper layer neurons in Pax6 deficiency is mostly attributable to a depletion of the progenitor pool, available for late neurogenesis. We further show that $\operatorname{Pax} 6^{f / f f l} ; E m x 1$-Cre mutants exhibited deficiencies in sensorimotor information integration, and both hippocampus-dependent short-term and neocortex-dependent long-term memory recall. Because a majority of the morphological and behavior disabilities of the Pax6 mutant mice parallel abnormalities reported for aniridia patients, a condition caused by PAX6 haploinsufficiency, the Pax6 conditional mutant mice generated here represent a valuable genetic tool to understand how the developmental cortical disruption can lead to a human behavior abnormality.

\section{Introduction}

The transcription factor Pax6 is a developmental regulator with an early embryonic forebrain expression pattern that is mostly limited to the pluripotent radial glial progenitors (RGPs) of the dorsal telencephalon (Götz et al., 1998; Walther and Gruss, 1991; Simpson and Price, 2002). These RGPs are responsible for generating the glutamatergic excitatory pyramidal neurons of the cortex (Peters and Jones, 1985). In Pax6-deficient Small eye embryos, the dorsoventral molecular patterning of the telencephalon is disrupted (Stoykova et al., 1996, 2000; Toresson et al., 2000;

Received Nov. 27, 2008; revised April 25, 2009; accepted May 18, 2009.

This work was supported by the Max Planck Gesellschaft (K.R., A.S.), the Deutsche ForschungsgemeinschaftCenter of Molecular Physiology of the Brain (T.C.T., A.S.), and Medical Research Council (M.C.P., Z.M.); the United Kingdom research of the R.A.-P. Laboratory is supported by the Israel Science Foundation, Binational Science Foundation, Israel Ministry of Health, E. Matilda Ziegler Foundation, and AMN Foundation. We thank K. Jones, J. Gorski, and A. Messing for providing the Emx1Cre and hGFAP-Cre mouse lines; and F. Guillemot, M. Lie, J. Liu, M. Price, T. Rabbitts, V. Tarabykin, S. Tole, and J. Rubenstein for the kind gifts of plasmid DNA. We also thank M. Daniel and S Eckert for the outstanding technical assistance.

*T.C.T. and K.R. contributed equally to this work.

Correspondence should be addressed to Anastassia Stoykova, Department of Molecular Cell Biology, Max Planck Institute for Biophysical Chemistry, Am Fassberg 11, 37077 Göttingen, Germany. E-mail: astoyko@gwdg.de.

K. Radyushkin's present address: Max Planck Institute of Experimental Medicine, Division of Clinical Neuroscience, Hermann-Rein-Strasse 3, 37075 Göttingen, Germany.

D01:10.1523/JNEUROSCI.5669-08.2009

Copyright $\odot 2009$ Society for Neuroscience $\quad 0270-6474 / 09 / 298335-15 \$ 15.00 / 0$
Yun et al., 2001; Muzio et al., 2002), and a substantial fraction of cortical (pallial) progenitors are respecified to produce interneurons (INs) at the expense of glutamatergic pyramidal neurons (Kroll and O'Leary, 2005). The expression gradient of Pax6 in the cortical ventricular zone (VZ) (Stoykova et al., 1997) suggests that Pax6 might confer rostral cortical area identities (O'Leary and Nakagawa, 2002). However, although molecular markers for caudal domains are expanded into rostral cortex in the absence of Pax6 function (Bishop et al., 2000; Piñon et al., 2008), the main cortical functional domains show normal thalamocortical connectivity, suggesting that the graded expression of Pax6 in RGPs does not impact intrinsic area identity (Piñon et al., 2008).

Cortical glutamatergic neurons are derived from two types of progenitors: RGPs, which divide asymmetrically at the apical surface of the VZ; and intermediate (or basal) progenitors (IPs), which originate from RG and divide symmetrically in the subventricular zone (SVZ) (Haubensak et al., 2004; Miyata et al., 2004; Noctor et al., 2004; Lukaszewicz et al., 2005). In Pax6-deficient mutant mice, RGPs generate only one-half the normal number of cortical neurons (Heins et al., 2002), and upper [supragranular layer (SGL), layer 4 (L4), L3, and L2] layers are almost completely absent (Schmahl et al., 1993; Stoykova et al., 1996; Carić et al., 1997; Götz et al., 1998; Tarabykin et al., 2001; Nieto et al., 2004; Schuurmans et al., 2004). In contrast, mutants deficient for the 
transcription factor Ngn2 exhibit selective defects in the specification and migration of the early-generated lower [infragranular layer (IGL), L6, and L5] neurons, implying that IGL and SGL neurons are specific outputs of Ngn2- and Pax6-controlled genetic pathways, respectively (Schuurmans et al., 2004) (for review, see Guillemot et al., 2006). Notably, however, recent evidence from analyses of $\mathrm{Pax} 6^{+/+} / \mathrm{Pax} 6^{-1-}$ chimeric mice have revealed a cell-autonomous role for Pax6 in the regulation of progenitor exit from mitosis during early neurogenesis, but the affected IGL neuronal lineages have not yet been identified (Quinn et al., 2007).

The neurons of each distinct cortical layer originate from pallial progenitors during embryogenesis [embryonic day 10 (E10) to E17 in mouse] (Takahashi et al., 1999), but they reach their final location, defined by their intrinsic identity, only after birth [postnatal day 8 (P8) in mouse]. Thus, the early prenatal lethality observed in Pax6/Small eye homozygous (Sey/Sey) mutants precludes a direct analysis of the role Pax6 plays in acquiring neuronal layer identity and hampers our understanding of the mechanisms that underlie the neurological deficiencies caused by Pax6 insufficiency in humans. To investigate Pax6 functions in the generation of cortical-layer diversity, we studied the cortical patterning of juvenile and adult cortical organization in viable Pax6 conditional knock-out (KO) mice. Intriguingly, removal of Pax6 during late neurogenesis does not affect SGL generation. However, the absence of Pax6 at the onset of neurogenesis leads to the expansion of specific neuronal lineages of the marginal zone (MZ) and IGLs, and ultimately to depletion of the progenitor pool available for late neurogenesis of SGLs and more active perinatal oligodendrogenesis. We further demonstrate that the misbuilding of the neocortex during development leads to profound neurological and memory deficits that parallel the disabilities reported in aniridia patients with Pax6 haploinsufficiency, suggesting that the severe SGL depletion might be the underlying basis for the memory deficiencies observed in humans.

\section{Materials and Methods}

Animals. A description of the generation of Pax $6^{\text {flox }}$, EMX1 ${ }^{\text {IRES-Cre }}$, and hGFAP-Cre mice has been published previously (Ashery-Padan et al., 2000; Zhuo et al., 2001; Gorski et al., 2002). Mice were maintained in a $\mathrm{C} 57 \mathrm{BL} / 6 \mathrm{~J}$ background. Animal handling was conducted with the permission of the Bezirksregierung Braunschweig in accordance with the German Animal Protection Law.

Antibodies. See supplemental Experimental Procedures (available at www.jneurosci.org as supplemental material).

In situ hybridization. Nonradioactive in situ hybridization was performed on $16 \mu \mathrm{m}$ sections from embryonic, postnatal (P10), or adult brains fixed in $4 \%$ paraformaldehyde and cryoprotected according to Moorman et al. (2001). The radioactive in situ protocol used is that of Stoykova and Gruss (1994).

Immunohistochemistry. Immunohistochemical procedures using a combination of peroxidase antiperoxidase and $\mathrm{ABC}$ techniques, as shown in Figures 2, $A$ and $A^{\prime}, 5 A-E^{\prime}$, and $6 A-B^{\prime}$, were performed as described previously (Davidoff and Schulze, 1990). For immunofluorescence, sections were incubated overnight with primary antibody at $4^{\circ} \mathrm{C}$ after blocking with normal sera of the appropriate species. Primary antibodies were detected with a fluorescent secondary antibody (Alexa Fluor; 1:400; Invitrogen). Sections were later counterstained with Vectashield mounting medium containing 4',6'-diamidino-2-phenylindole (DAPI) (Vector Laboratories) to label nuclei.

5-Bromo-2'-deoxyuridine labeling. Pregnant mice were injected with 5-bromo-2'-deoxyuridine (BrdU) $(140 \mu \mathrm{g} / \mathrm{g})$. For pulse labeling of IGL neurons, pregnant mice were injected at $\mathrm{E} 12$ and embryos were fixed at E15. SGL neurons were pulse labeled by injecting pregnant mice at E16.5 (time of peak SGL generation) or E18.5 (time dominated by L2-L3 gen- eration). Newborns of injected mice were killed at P10. Cell cycle exit was analyzed by injecting pregnant mice at E13 and fixing embryos at E14.

Image analysis. See supplemental Experimental Procedures (available at www.jneurosci.org as supplemental material).

Behavioral tests. Three-month-old mice were evaluated using a battery of behavioral tests, including elevated plus maze, open field, rotarod, hot plate, tail flick, prepulse inhibition, buried food finding, and contextual and cued-fear conditioning. Tests were performed in the same order as listed above. Male mice (14 mutants and 15 wild type) were used for testing. In addition, two separate cohorts of animals (12 mutants and 11 wild-type mice each) were used to test remote memory for cued fear and extinction of cued fear. All testing was done in a sound-attenuated room between 9:00 A.M. and 5:00 P.M. Mice were group housed with ad libitum access to food and water with a $12 \mathrm{~h}$ light/dark cycle (light phase onset at 7:00 A.M.).

For details, see supplemental Experimental Procedures (available at www.jneurosci.org as supplemental material).

\section{Results}

\section{Pax6 modulates neurogenesis of the Reelin + sublineage of the MZ}

The neurons of the PPL (preplate) are the earliest-born neurons in the developing cortex (E10 in mouse), and subsequently separate into MZ and subplate (SP) (Bayer et al., 1991). The MZ is predominantly comprised of Reelin + Cajal-Retzius (CR) cells, the majority of which also exhibit Calretinin and Tbr1 immunoreactivity (Hevner et al., 2003b). Previous data indicated that, in the absence of Pax6, the MZ of the Sey/Sey embryonic cortex contains an increased number of Reelin +/Calretinin + neurons, which possibly originate from the remnant vesicles of the missing olfactory bulbs (OBs) (Stoykova et al., 2003). To determine whether the expression of Pax6 in cortical progenitors could intrinsically influence the generation of MZ neurons, we analyzed the MZ in cortex-specific conditional Pax6 mutant (Pax6 $6^{f l f l}$; Emx1-Cre) (Piñon et al., 2008) (designated thereafter Emx1-Cre/ Pax6cKO), which have normally developed olfactory bulbs (Piñon et al., 2008). Quantitative analysis of the Reelin-, Calretinin-, and Tbr1-expressing cells was conducted by immunolabeling at E15.5, because Reelin expression diminishes after birth. In the $\mathrm{MZ}$ of Emx1-Cre/Pax $6 \mathrm{cKO}$, the numbers of all three types of neurons were significantly elevated: Reelin + cells increased from $15.5 \pm 1.2$ cells/field to $25.2 \pm 1.7$ cells/field $(p=0.020 ; n=4$ mice/genotype); Calretinin + cells increased from $15.8 \pm 2.3$ to $24.5 \pm 2.4$ cells/field ( $p=0.019 ; n=4$ mice/genotype); and Tbr $1+$ cells increased from $24.8 \pm 1.8$ to $36.2 \pm 1.6$ cells/field ( $p=0.017 ; n=4$ mice/genotype) (Fig. $1 A, A^{\prime}, B, B^{\prime}, C, C^{\prime}$ ). Consistent with data indicating that most Reelin + cells in the $\mathrm{MZ}$ are also Tbr1+ (Hevner et al., 2003b), the number of neurons expressing both Tbr1 and Reelin was significantly increased (supplemental Fig. 1, available at www.jneurosci.org as supplemental material). Thus, in Pax6 deficiency, the pallial RGPs apparently generate an enhanced number of Reelin+/Calretinin +/Tbr1+ neurons in the MZ by a cell-autonomous mechanism. In agreement with previous reports that the Emx1-Cre line drives effective recombination at a time early enough in embryogenesis to allow investigation of the neurogenesis of preplate neurons (Gorski et al., 2002; Li et al., 2003), we found that Calretinin + cells were almost missing at SP location in the mutant cortex, which was especially evident in rostral neocortex (Fig. $1 B, B^{\prime}$ ). The Reelin+ cells of the MZ are progeny of the Emx1-Cre line cell lineage (Gorski et al., 2002). Interestingly, the Reelin + cells in the MZ and a subset of L5 neurons that express the ETS transcription factor Er81, have been shown to have a common ancestor (Shen et al., 2006). We have previously demonstrated that the Er81 gene 

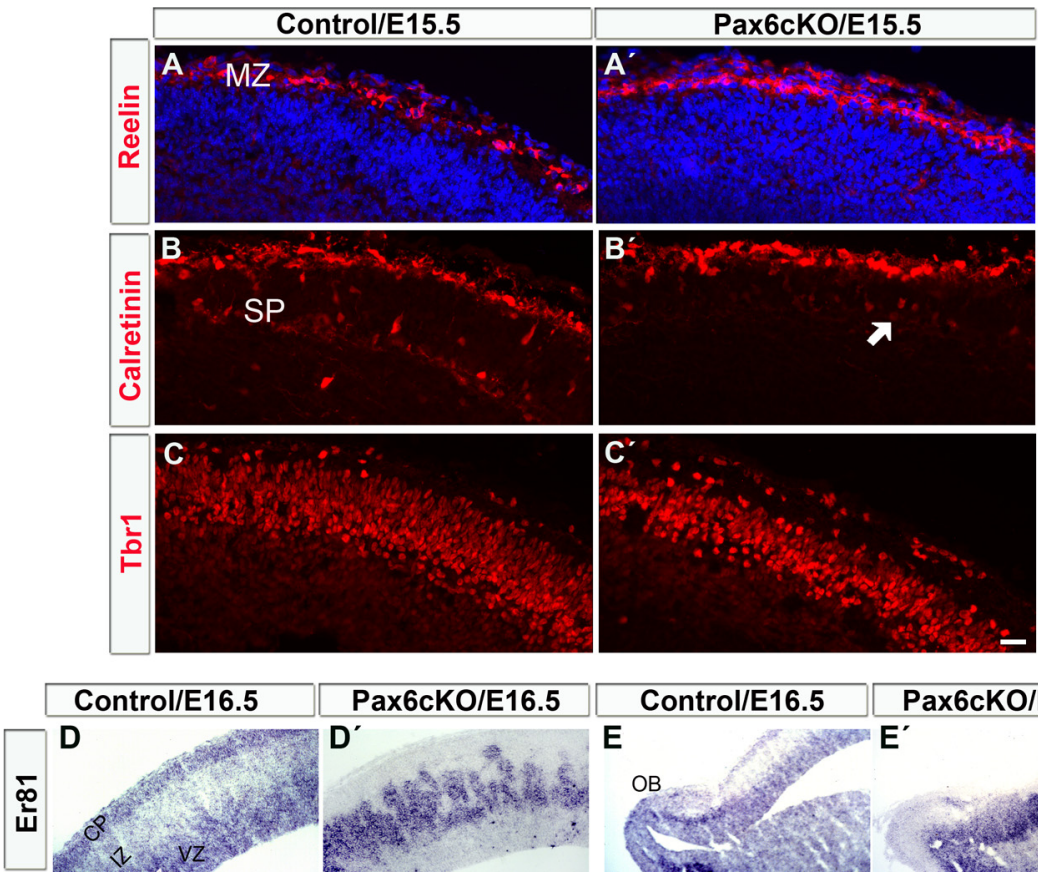
$\mathbf{E}^{\prime}$

Figure 1. Increased number of neuronal subsets in the MZ of Emx1-Cre/Pax6CKO mutant mice. A-C', Sagittal sections from Emx1-Cre/Pax6CKO and control embryo brains at stage E15.5 were immunostained for Reelin, Calretinin, and Tbr1 as indicated. The arrow in $\boldsymbol{B}^{\prime}$ points to only few Calretinin + cells in the presumptive SP of the mutant cortex. $\boldsymbol{D}-\boldsymbol{E}^{\prime}$, Sagittal sections from E16.5 control and mutant embryo brains showing in situ hybridization signals detected with an Er81 probe. In $\boldsymbol{D}$ and $\boldsymbol{D}^{\prime}$, note the complete abrogation of Er81 expression in pallial progenitors in the VZ and CP of Emx1-Cre/Pax6cKO mice. However, a thick band of Er81+ cells is seen in the SVZ/IZ of the mutant, showing a direct connection between the SVZ and the fronto-orbital cortex/ olfactory bulb $\left(\boldsymbol{E}, \boldsymbol{E}^{\prime}\right)$. Scale bar: (in $\left.\boldsymbol{C}^{\prime}\right) \boldsymbol{A}-\boldsymbol{C}^{\prime}, 25 \mu \mathrm{m}$.

is a downstream target of Pax6 in pallial progenitors (Tuoc and Stoykova, 2008a). As expected, cortical expression of Er81 in the VZ of $\mathrm{Pax}^{f l f l}$;Emx1-Cre mice was fully abolished (Fig. $1 \mathrm{D}, \mathrm{D}^{\prime}$ ); however, there was a strikingly thick band of Er81+ cells in the SVZ/intermediate zone (IZ) connected to OB (see Fig. $4 E, E^{\prime}$ ). Together, these findings strongly suggest that, in the absence of Pax6, the Reelin $+/$ Er81 + lineage generates an enlarged set of Reelin $+/$ Calretinin $+/$ Tbr $1+$ neurons, possibly at the expense of Er81+ L5 neuronal progeny.

\section{Pax6 controls the size of specific IGL neuronal lineages}

The role of Pax6 in specification of IGL sublineages was controversial. Analyses of the molecular patterning of IGLs in Sey/Sey embryos did not reveal substantial abnormalities (Stoykova et al., 2000; Tarabykin et al., 2001; Schuurmans et al., 2004). In contrast, premature cortical neurogenesis at early developmental stages was documented in Pax6-deficient embryos (EstivillTorrus et al., 2002; Quinn et al., 2007), suggesting that Pax6 may also play a role in the generation of lower-layer neurons. To determine the role of Pax6 in the formation of IGL neuronal lineages, we analyzed expression of markers, indicative of lower and upper neuronal subtypes in Emx1-Cre/Pax6cKO mutant and control brains at stage P10, a time when neuronal migration is completed, for expression of a panel of markers for lower- and upper-neuronal subtypes. Immunohistochemical analysis of the neuron-specific enolase (NSE), revealed a clearly enhanced presence of large L5 pyramidal neurons, as well as a retention of NSE + cells in the subcortical white matter above the hippocampus (Hi) (see Fig. 3A, $A^{\prime}$, arrows). Similarly, transcripts for the vesicular glutamate transporter 1 (Vglut 1 ), which is expressed in all glutamatergic neurons, were detected in a thicker band of L5
Pax6cKO/E16.5

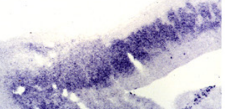

neurons ectopically located at the uppermost position in the mutant cortical plate (CP) (see Fig. $3 B, B^{\prime}$ ). Vglut1+ cell aggregates were also detected within the subcortical white matter, which also contains fibers of the radiatio corporis callosi (see Fig. $3 B, B^{\prime}$, arrows), the hippocampal SVZ and the posterior periventricular (pPV) zone (data not shown). These findings suggested that augmented set of IGLs are present in the juvenile Emx1-Cre/ Pax6cKO cortex.

We next wanted to investigate whether specific IGL neuronal sublineages were affected in the Emx1-Cre/Pax6cKO mice. At early postnatal stages, expression of the transcription factor Tbr 1 is high in L6 neurons and low in L5 neurons (Bulfone et al., 1999; Hevner et al., 2003a), whereas Ctip2, encoding a zinc-finger protein, is exclusively expressed in L5 neurons, labeling all corticospinal projection motor neurons (CSMNs) (Arlotta et al., 2005). Colabeling of brain sections with antibodies for Tbr1 and Ctip2 at P1 (Fig. $2 C-G^{\prime}$ ) showed an increase in these two IGL neuronal subpopulations in the mutant particularly evident in the rostral cortex. Counting of immunopositive cells in equally sized fields, spanning the entire thickness either of layer 6 (for Tbr1) or layer 5 (for Ctip2), revealed a significant increase of both lineages in the mutant compared with paired control brains (Fig. $\left.2 C-G^{\prime}\right)$. The number of Tbr $1+\mathrm{L} 6$ neurons per field was $367 \pm 12$ in controls and $410 \pm 11$ in mutants $(p=0.012 ; n=3$ micel genotype) in the dorsal pallium (DP), and $174 \pm 14$ in controls and $152 \pm 12$ in mutants ( $p=0.125 ; n=3$ mice/genotype $)$ in the lateral pallium (LP). The number of Ctip $2+$ L5 neurons per field was $126 \pm 12$ in controls and $183 \pm 7$ in mutants $(p=0.0005$; $n=3$ mice/genotype) in the DP, and $87 \pm 6$ in controls and $114 \pm 8$ in mutants ( $p=0.009 ; n=3$ mice/genotype) in the LP. In contrast, the expression of the transcription factor, Satb2, known to control the expression of Ctip2 (Alcamo et al., 2008; Britanova et al., 2008), was substantially diminished in Emx1Cre/Pax6cKO brains (Fig. $2 B, B^{\prime}$ ).

To further address the production of neurons occupying the L5 laminar position, we characterized the expression of genes considered to be markers for L5 neuronal subsets. Expression of the transcription factor forebrain embryonic zinc finger-like (Fezl), which is normally expressed in almost all layer 5 CSMNs (Molyneaux et al., 2005), was expanded in the Emx1-Cre/ Pax6cKO cortex (Fig. 3C, $C^{\prime}$ ). Similarly, expressions of the transcription factors, $I d 2$ (Fig. $3 D, D^{\prime}$ ), and $L m o 4$ (see Fig. $5 B, B^{\prime}$ ), were much more broadly distributed in L5 neurons in the mutant. Interestingly, the region expressing the LIM-HD transcription factor cofactor, Clim 1a, which is normally restricted only to a deeper portion of L5 (Bulchand et al., 2003), was markedly enlarged in both juvenile (Fig. $3 E, E^{\prime}$ ) and adult 8-month-old mutant brains (Fig. $3 F, F^{\prime}$ ). Moreover, double immunostaining for Clim1/Lbd2 and NeuN revealed a significant increase in the number of Clim1 $+/ \mathrm{NeuN}+$ neurons in the adult Emx1Cre/ Pax6cKO mice (supplemental Fig. 2, available at www.jneurosci. org as supplemental material). The broader expression of Clim 1a 

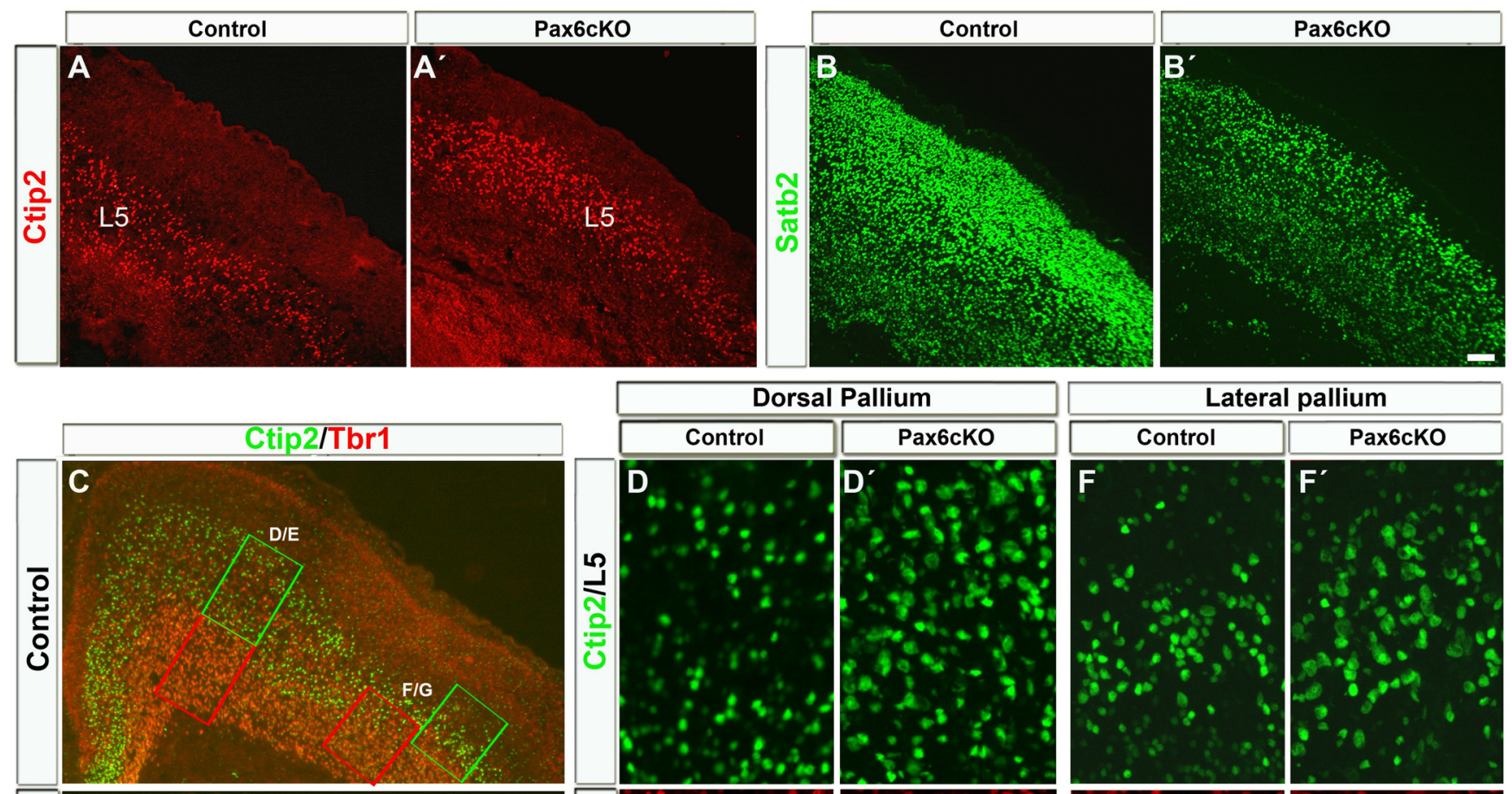

Pax6cko
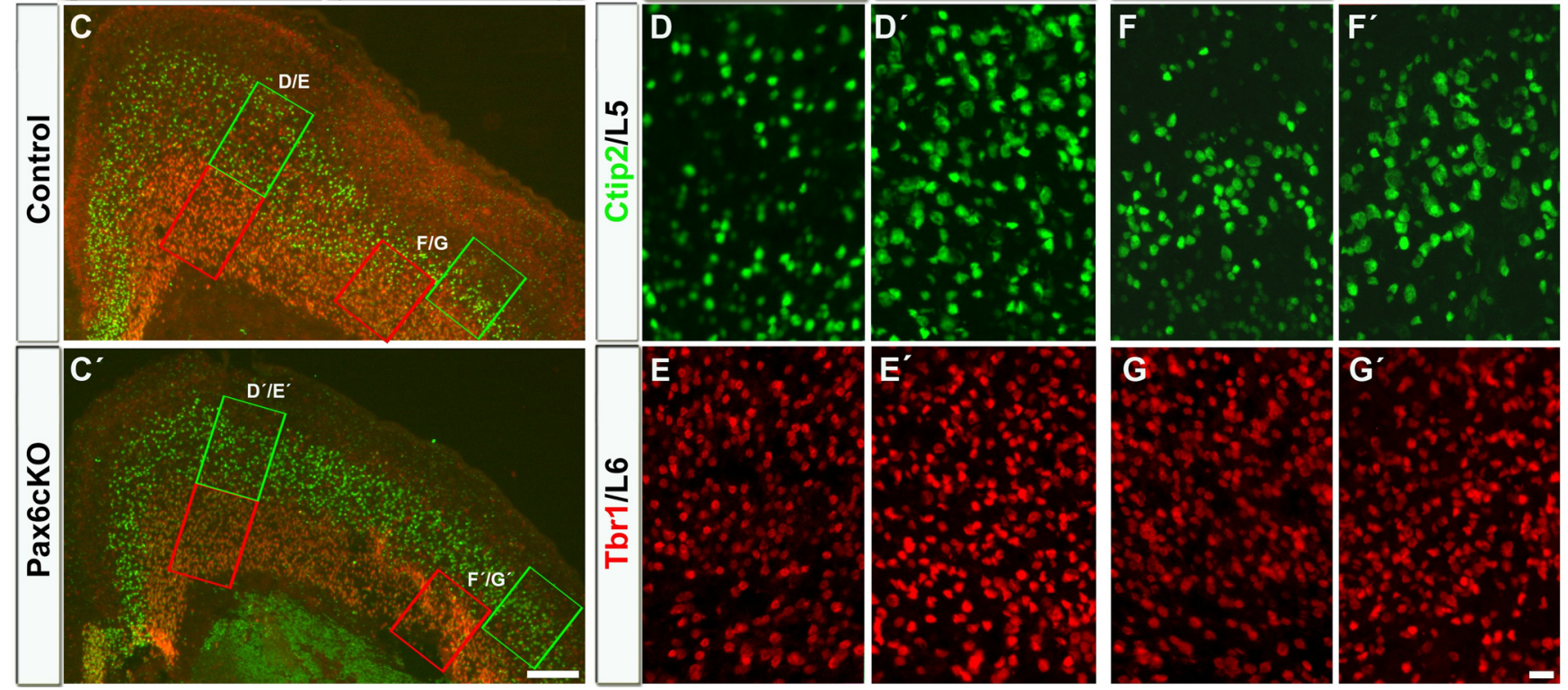

Figure 2. Increased number of IGL neurons in the cortex of juvenile Emx1-Cre/Pax6cKO mice. $A-\boldsymbol{B}^{\prime}$, Immunostaining for Ctip2 (red) and Satb2 (green) reveals increase in the number of Ctip2+ L5 neurons $\left(\boldsymbol{A}, \boldsymbol{A}^{\prime}\right)$ and a severe reduction of Satb2 + neurons $\left(\boldsymbol{B}, \boldsymbol{B}^{\prime}\right)$ in the P1 cortex of Emx1-Cre/Pax6cKO mice. $\boldsymbol{C}-\boldsymbol{G}^{\prime}$, Double immunostaining for Tbr1 (red) and Ctip2 (green) on coronal sections of control $(\mathbf{C}-\mathbf{G})$ and mutant $\left(\boldsymbol{C}^{\prime}-\mathbf{G}^{\prime}\right)$ brains at stage P1 reveals an increase in the number of strongly labeled Tbr1+ $\mathrm{L} 6$ and $C$ tip2 $+\mathrm{L} 5$ neuronal sets in the mutant cortex, as indicated in the corresponding diagrams. Scale bars: (in $\boldsymbol{B}^{\prime}$ ) $\boldsymbol{A}-\boldsymbol{B}^{\prime}, 200 \mu \mathrm{m}$; (in $\boldsymbol{C}^{\prime}$ ) $\boldsymbol{C}, \boldsymbol{C}^{\prime}, 200 \mu \mathrm{m}$; (in $\boldsymbol{G}^{\prime}$ ) $\boldsymbol{D}-\boldsymbol{G}^{\prime}, 20 \mu \mathrm{m}$.

in L5 observed in the mutant brain is intriguing because Clim1a and the transcription factor $L h \times 2$ are expressed in a complementary manner in IGLs and SGLs, suggesting a mutual cross-regulation between these genes (Bulchand et al., 2003). Notably, we detected large gaps in the $L h \times 2$-positive lineages in the rostral Pax6cKO cortex at prenatal (E17.5) and juvenile stages (supplemental Fig. 3A-B', available at www.jneurosci.org as supplemental material). Additional experiments will be needed to clarify whether these genes exert mutual control over one another via a Pax6-dependent mechanism.

It is important to notice that the expression of transcription factor Otx1, another L5 neuronal maker, was not changed in absence of Pax6 in VZ of embryonic Sey/Sey cortex (Tarabykin et al., 2001). Similarly, the expression of both, Otx1 (data not shown) and Nurrla, a marker for L6a neurons, appeared unchanged in the juvenile cortex of Emx1-Cre/Pax6cKO (supplemental Fig. $3 C, C^{\prime}$, available at www.jneurosci.org as supplemental material). Collectively, these results suggest that Pax6 could selectively modulate the size of distinct IGL neuronal sublineages.

\section{Premature early neurogenesis in the cortex of}

\section{Emx1-Cre/Pax6cKO mice}

Laminar cell fate determination and cell cycle progression are tightly coordinated processes (McConnell and Kaznowski, 1991;
Caviness et al., 2003). Results from a study of corticogenesis in Pax $6^{-/-} / \mathrm{Pax}^{+/+}$chimeric embryos demonstrated that, during early neurogenesis, $\mathrm{Pax}^{-/-}$progenitors exit prematurely from the mitotic cycle, thus affecting differentiation of the early arising, lower-layer neurons (Quinn et al., 2007). Because mitotic cycle parameters are dependent on thalamocortical connectivity (Dehay and Kennedy, 2007), showed to be abnormal in Pax6LOF mutants (Jones et al., 2002), we reinvestigated whether Pax6 autonomically controls progenitor cell cycle exit using cortical samples from Emx1-Cre/Pax6cKO and control embryos. After extended BrdU pulse labeling, cells that reenter mitosis are much more lightly labeled than postmitotic cells (Roy et al., 2004; Cubelos et al., 2008). To test the timing of cell cycle exit, we injected pregnant mice of both studied genotypes with BrdU at E13.0 and tested BrdU incorporation $24 \mathrm{~h}$ later. As shown in Figure $4 A-C^{\prime}$, the number of brightly labeled BrdU+ cells in equally sized fields, spanning the entire thickness of the $\mathrm{CP}$, was significantly greater in the DP of mutant mice (61 \pm 1.3 cells/ field) than in controls ( $22 \pm 2$ cells/field; $p=0.019 ; n=3$ mice/ genotype). Furthermore, the percentage of brightly stained BrdU + cells among all DAPI-stained cells was significantly higher in the mutants $(29.84 \pm 4.34 \%)$ than in controls $(12.6 \pm$ $1.1 \% ; p=0.016 ; n=3$ per genotype), a difference that was particularly striking in the SVZ/IZ region (Fig. 4, histogram, bins 


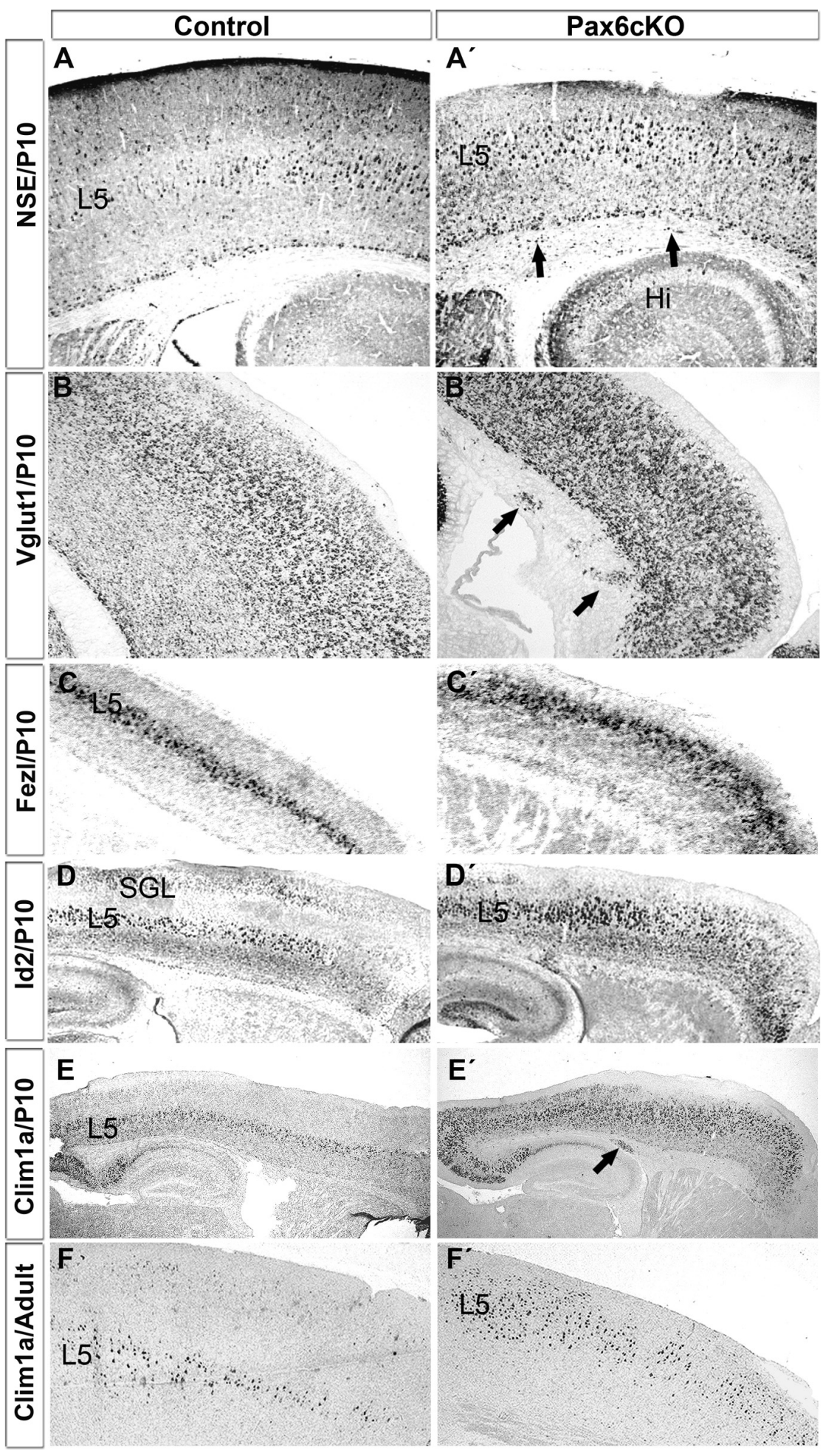

Figure 3. IGL neuronal sublineages show broader expression in the Emx1-Cre/Pax6cKO cortex. $A, A^{\prime}$, Immunostaining for NSE at P10 shows an increased number of large pyramidal cells at the uppermost position in the mutant $\left(\boldsymbol{A}^{\prime}\right)$ compared with that in the control $(\boldsymbol{A})$ cortex. $\boldsymbol{B}-\boldsymbol{E}^{\prime}$, Sagittal sections from P10 control and mutant brains showing hybridization of specific in situ probes for gene markers of subsets of $L 5$ neurons, as indicated. In $\boldsymbol{C}_{,} \boldsymbol{C}^{\prime}, \boldsymbol{D}, \boldsymbol{D}^{\prime}, \boldsymbol{E}$, and $\boldsymbol{E}^{\prime}$, note the enlarged zone of expression of Fezl + , Id2 + , and Clim $1 a+$ sets of $\mathrm{L} 5$ neurons in the mutant cortex. $\boldsymbol{F}, \boldsymbol{F}^{\prime}$, Illustration of the enhanced expression of Clim $1 \mathrm{a}$ in cross sections from 8-month-old adult brains. The arrows in $\boldsymbol{B}^{\prime}$ and $\boldsymbol{E}^{\prime}$ indicate cells trapped below the CP.

2-9). Consistent with previous data for Pax6-deficient embryos (Haubst et al., 2004; Quinn et al., 2007), we found that the number of cells in mitosis, labeled by an anti-phosphohistone $\mathrm{H} 3$ antibody, was significantly increased in the SVZ/IZ region of the mutant cortex, but remained similar to that of the control at the ventricular surface (Fig. $4 E, E^{\prime}, F$ ). To further investigate whether the changed pattern of progenitor proliferation in Emx1-Cre/Pax6cKO mice affects early-born lineages, we performed BrdU labeling of pregnant mice at the peak of IGL neurogenesis (E12.5) and analyzed the number of Tbr1 + L6/L5 neurons that reached the CP $72 \mathrm{~h}$ later. Quantification of cells double immunolabeled for Tbr1 and BrdU revealed a significantly higher proportion of BrdU+/Tbr1+ neurons in mutant compared with control mice (supplemental Fig. 4, available at www.jneurosci. org as supplemental material).

Together, these findings suggest that, instead of reentering mitosis, a larger proportion of early RGPs in the Pax6deficient cortex undergo neurogenic division to generate IGL neurons and surplus of IPs, thus increasing the early-born IGL neuronal identities (e.g., Clim1a+ L5a, Tbr1+ L6, Ctip2+ L5, Fezl+ L5).

\section{Absence of Pax6 causes SGL dysgenesis but does not affect the specification of upper-layer neuronal fate}

It has been previously proposed that the embryonic Sey/Sey mutant cortex is depleted of SGL neurons because of migratory defects (Carić et al., 1997). Here, we reinvestigated how the loss of Pax6 at the onset of neurogenesis influences the cortical patterning in the juvenile Emx1-Cre/ Pax $6 c K O$ and control mice, and thus alters the final allocation of the neurons in SGLs.

Immunostaining for NeuN revealed a substantial reduction of SGLs in the Emx1Cre/Pax6cKO cortex (Fig. 5A, $A^{\prime}$ ). Expression of $L m o 4$ was nearly absent in the upper layers of the rostral cortex in $\mathrm{Pax} 6 \mathrm{CKO}$ but showed broader expression within the L5 domain (Fig. $5 B, B^{\prime}$ ). The laminar organization was further assessed by analysis of the expression of several layer-specific genes: $R Z R \beta$ for L4 (Schaeren-Wiemers et al., 1997), and EphA4 (Nakagawa et al., 1999), Cux1, Cux2 (Zimmer et al., 2004), and Svet1 (Tarabykin et al., 2001) for L4L2. In the Emx1-Cre/Pax6cKO cortex, the expression of $R Z R \beta, \quad E p h A 4$ (Fig. $5 C, C^{\prime}, D, D^{\prime}$ ), and Svet1 (supplemental Fig. $3 D, D^{\prime}$, available at www.jneurosci. org as supplemental material) was reduced; Cux2 (Fig. 5E, E') and Cux1 (data not shown) transcripts were undetectable.

To test the migratory ability of SGL neurons in the postnatal Pax6cKO cortex, we performed BrdU pulse labeling at E16.5 during the peak SGL generation and at E18.5, when L3-L2 are still actively being generated (Fig. $5 F-G^{\prime}$ ). At both stages, there was a severe depletion of SGLs in the mutant, and the germinal epithelium (GE) contained 

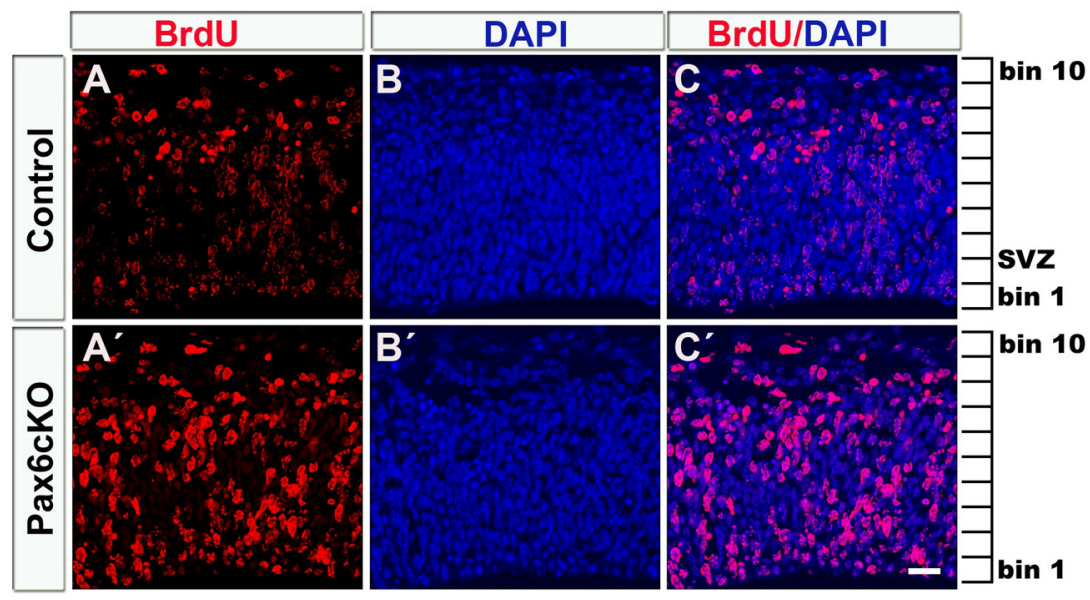

D

Bright BrdU cells - 24h BrdU (E13 >E14)
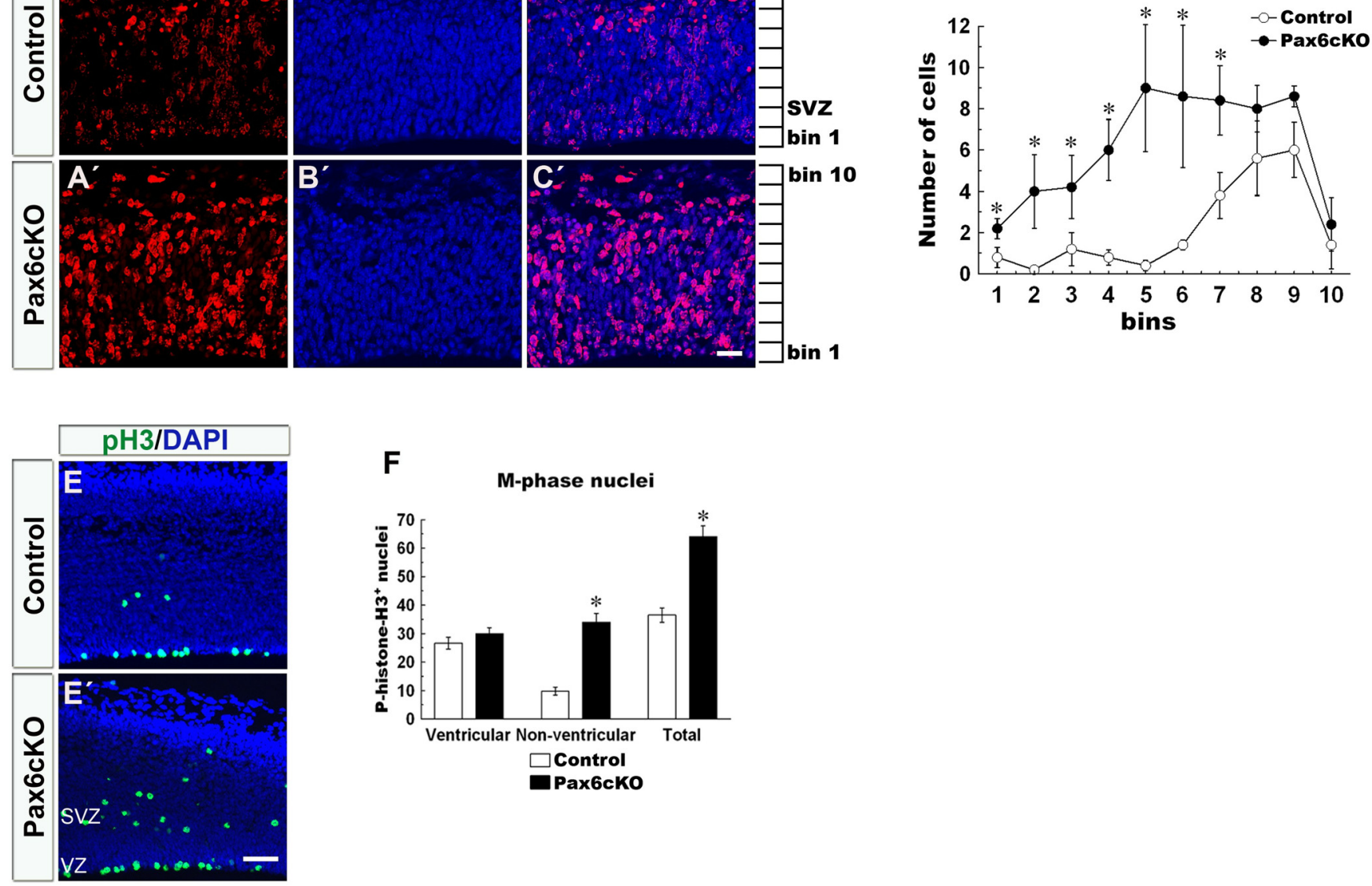

Figure 4. Premature cell cycle exit of progenitors in Emx1-Cre/Pax6cKO mice during early neurogenesis. BrdU was injected at E13 and brains were fixed and analyzed $24 \mathrm{~h}$ later. $A-C^{\prime}$, Confocal images of sections from control and mutant DP after BrdU immunostaining or DAPI staining. Cells that reenter mitosis are much less intensely labeled than the brightly labeled BrdU + cells that become postmitotic after their terminal division. In $\boldsymbol{A}-\boldsymbol{C}^{\prime}$, note that the mutant cortex contains much more brightly labeled BrdU + cells, compared with the controls. $\boldsymbol{D}$, The cortical anlage was divided into 10 vertical bins of equal thickness. The histogram shows a statistical analysis of the number of brightly labeled BrdU + cells in each cortical region (bin 1, VZ; bins 2 and 3, SVZ; bins $4-7$, IZ; bins 8-9, (P; bin 10, MZ) in mutant and control cortex as indicated. Error bars indicate SEM. E, $\boldsymbol{E}^{\prime}$, Phosphorylated histone H3 (pH3) immunolabeling of sections from control and mutant dorsal telencephalon. Note the increased number of nonventricular (SVZ and IZ) pH3 + cells confirmed by statistical analysis (in $\boldsymbol{F}$ ). ${ }^{*} p<0.05$. Scale bars: (in $\left.\boldsymbol{C}^{\prime}\right) \boldsymbol{A}-\boldsymbol{C}^{\prime}, 20 \mu \mathrm{m}$; (in $\boldsymbol{E}^{\prime}$ ) $\boldsymbol{E}, \boldsymbol{E}^{\prime}, 10 \mu \mathrm{m}$.

significantly more BrdU + cells. Notably, none of the SGL genes were detected to be expressed ectopically in SGL in the Emx1-Cre/ Pax6cKO cortex at P10 or even 3 months after birth, either in ectopic lower positions of the $\mathrm{CP}$ or in the augmented GE at the pallial-subpallial border (PSPB) (data not shown). These findings rule out misallocation of correctly differentiated SGL neurons in the Pax6cKO cortex.

To directly determine whether Pax6 has a role in the differentiation of late RGs into SGL neuronal identities, we produced Pax6 conditional KO mice using the hGFAP-Cre transgenic line (Zhuo et al., 2001). The hGFAP-Cre line has been shown to drive effective recombination in almost all Pax6 $+/ R G$ progenitors in the developing cortex starting at stage E13.5 (Malatesta et al., 2003). Indeed, a Western blot analysis of samples isolated from the cortices of E14.5 and E16.5 embryos (i.e., at peak SGL neuronal production) indicated that residual Pax6 expression in $\operatorname{Pax}^{\mathrm{fl} / f}$; $h G F A P$-Cre mutant mice (named thereafter $h$ GFAP-Cre/Pax6cKO) was reduced to 28 and $15.3 \%$ that of control mice at E14.5 and E16.5, respectively (supplemental Fig. 5, available at www. jneurosci.org as supplemental material). We also assessed the expression of Tbr 1 in both IGLs and SGLs, and the expression of Cux1 and Ctip2 in SGLs and IGLs, respectively, in sections from
P10 mutant and control brains. Intriguingly, the elimination of Pax6 function after the generation of IGL neurons did not affect either the specification or the number of the resulting SGL neuronal lineages. During the progression of neuronal differentiation, Pax6 expression strongly declines after E14.5 at both the transcriptional and translational level (Tuoc and Stoykova, 2008b). Together, these findings suggest that the low level of Pax6 in late RGPs does not play an important role in the specification of SGL versus IGL neuronal fate.

Defects in differentiation of late-prenatal and postnatal RG progenitors in Emx1-Cre/Pax6cKO mutant

The brain of the juvenile (P10) Emx1-Cre/Pax6cKO mouse contains dense cell masses at the PSPB (Piñon et al., 2008). These large cell protrusions were strongly labeled by the subpallial markers, Dlxl (Fig. 6D) and Arx (Fig. $6 H, H^{\prime}$ ), reflecting the ventralization of the cortical neuroepithelium in Pax6 LOF mutants (Stoykova et al., 2000; Yun et al., 2001; Kroll and O'Leary, 2005) (see also supplemental Fig. $6 A, A^{\prime}$, available at www. jneurosci.org as supplemental material). As a consequence, the fronto-orbital, frontal, and the somatosensory cortices of Emx- 


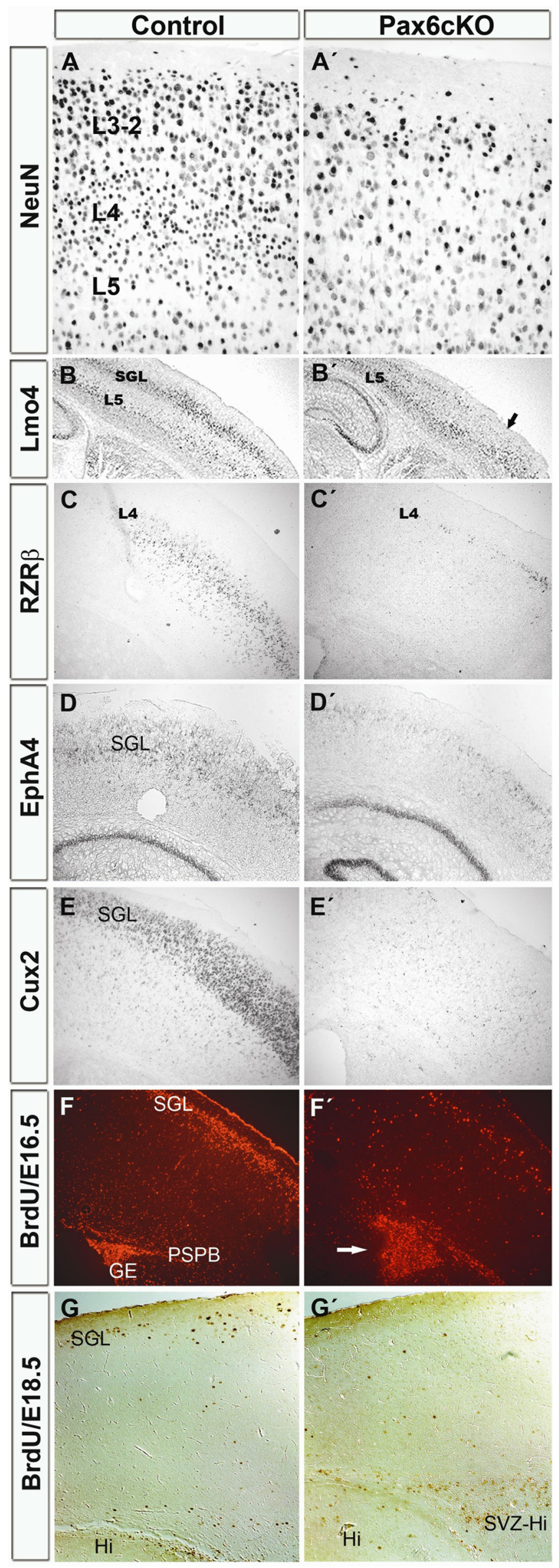

Cre/Pax6cKOs mice contain enlarged sets of GABAergic INs of both Arx + and GAD67+ types (Fig. 6H, $H^{\prime}, I, I^{\prime}$ ).

Late RGPs (E16-E19) generate SGL neurons, astrocytes, and oligodendrocytes, whereas a small subset of RG maintains progenitor properties even during early postnatal stages (Levers et al., 2001). Immunostaining for Nestin and GFAP, two markers for progenitors within the PSPB and rostral migratory stream (RMS) of the adult brain, revealed an excess of Nestin + progenitors (Fig. 6A, $A^{\prime}$ ) and GFAP+ astrocyte-like cells (Fig. $6 B, B^{\prime}, J, J^{\prime}$, arrow) in Emx1-Cre/Pax $6 c K O$ mice. The thickness of the RMS was enlarged in the mutant brain and the RMS expressed abundantly the stem cell marker, Musashil (Msi1) (Fig. $6 C$ ). The vast majority of cells in the aggregates at the PSPB in Emx1-Cre/Pax6cKO were positive for Doublecortin (Dcx), a marker for immature neurons (Fig. 6E), and contained an increased number of actively proliferating cells at the pallial site (Fig. 6F, arrow) (data not shown). Double immunostaining for Ki67 and Dcx (Fig. 6G) revealed that many cells exhibited simultaneous nuclear Ki67 and cytoplasmic Dcx staining, suggesting that progenitor/stem-like cells accumulated at the PSPB in Pax6cKO mice are capable of undergoing differentiation, at least to the immature neuron stage.

In addition to staining astrocytes with stem cell properties within the SVZ/RMS (Doetsch et al., 1999), the GFAP antibody also labels differentiated cortical parenchymal astrocytes, which are normally evident at E18.5 in the uppermost CP (Choi, 1988). The juvenile cortex of Emx1-Cre/Pax6cKO mice exhibited a clear reduction in GFAP+ parenchymal astrocytes compared with controls (Fig. 6J, $J^{\prime}$, arrowhead), a finding that was also confirmed in the adult Emx1-Cre/Pax6cKO brain (data not shown). A significant fraction of cortical oligodendrocytes are defined by the expression of Olig1/Olig2 at E13.5 in the GE of the ventral forebrain, from which they migrate to the $\mathrm{CP}$ to participate in myelination of the gray matter (Nishiyama et al., 1996; Takebayashi et al., 2000). In contrast to GFAP, the transcription factor Olig1, a marker for developing and adult oligodendrocytes (Zhou et al., 2000), labeled a much thicker band of cells in the Emxl$\mathrm{Cre} / \mathrm{Pax} 6 \mathrm{KO}$ cortex (Fig. $6 \mathrm{~K}, \mathrm{~K}^{\prime}$ ). Interestingly, a much thicker band of cells positive for myelin basic protein (MBP) antibody, a marker for mature oligodendrocytes, was observed at such uppermost position in the adult cortex of Emx1-Cre/Pax6cKO mice (Fig. 7G,H), suggesting an increase of oligodendrogenesis in the Pax6-deficient brain. To study whether the prenatal RGPs in Emx1-Cre/Pax6cKO mice also have an enhanced capacity to generate oligodendrocytes, we performed BrdU pulse labeling at stage E18.5, and double immunostained sections from mutant and control P10 brains using antibodies for BrdU and $S 100 \beta$ protein. In early postnatal mouse telencephalon, $S 100 \beta$ is preferentially expressed in oligodendrocyte progenitors and maturat-

Figure 5. Dysgenesis of SGLneurons in the Emx1-Cre/Pax6cKO cortexatP10.A, $A^{\prime}$, Immunostaining of cross sections for NeuN reveals only a few cells at a position corresponding to the SGLs (L4-L2) in the mutant neocortex with large empty spaces between cells. $\boldsymbol{B}, \boldsymbol{B}^{\prime}$, Labeling of sagittal sections with an in situ probe for $L$ mo4 shows dysgenesis of SGLs in the frontal and parietal cortex ( $\boldsymbol{B}^{\prime}$, arrow) of the mutant mice and a broader band of $L m 04+$ cells at a position corresponding to $L 5 . C-E^{\prime}$, Analysis of cross sections by in situ hybridization with markers for all SGLS (L4-L2) reveals a severe attenuation (EphA4) $\left(\boldsymbol{D}, \boldsymbol{D}^{\prime}\right)$ or a complete abolishment $(C u x 2)\left(\boldsymbol{E}, \boldsymbol{E}^{\prime}\right)$ of the upper layers in the Emx1-Cre/Pax6cKO mutant. $C, C^{\prime}$, The expression of $R Z R \beta$ in $L 4$ neurons is severely diminished in the mutant. $\boldsymbol{F}, \boldsymbol{F}^{\prime}$, BrdU birthdating at E16, when mostly L4 neurons are labeled, or at stage $\mathrm{E} 18.5\left(\mathbf{G}, \mathbf{G}^{\prime}\right)$, when mostly $L 3 / L 2$ neurons are labeled, reveals a severe attenuation of generation of $S G L$ neurons in the mutant. Note that an enlarged progenitor pool is retained in the mutant GE at the PSPB ( $\boldsymbol{F}^{\prime}$, arrow) and in hippocampal SVZ (SVZ-Hi). 

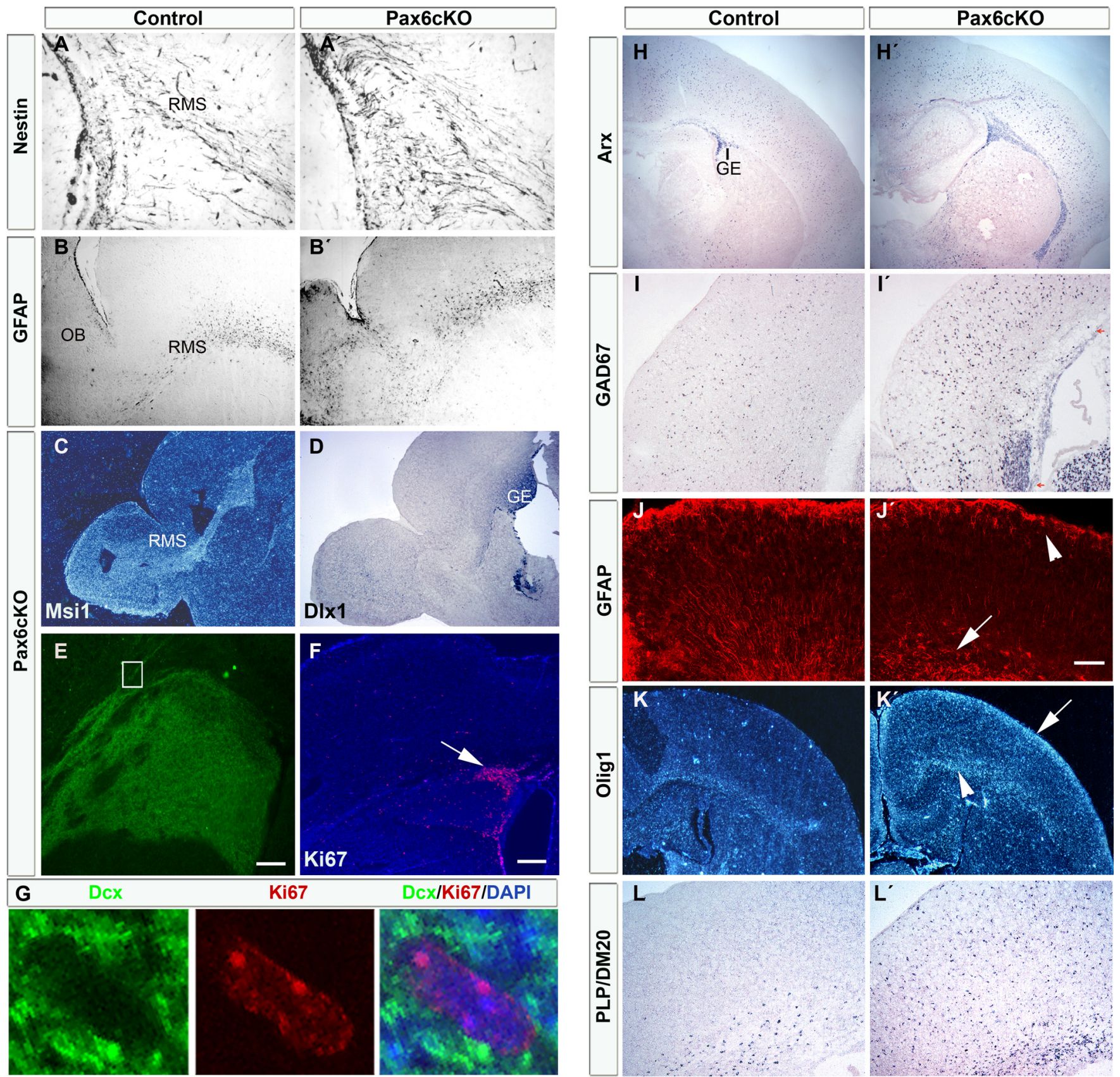

Figure 6. Differentiation defects of late prenatal and juvenile RG progenitors in the Emx1-Cre/Pax6cKO cortex. $\boldsymbol{A}-\boldsymbol{C}$, Immunostaining for Nestin $\left(\boldsymbol{A}, \boldsymbol{A}^{\prime}\right)$ and GFAP $\left(\boldsymbol{B}, \boldsymbol{B}^{\prime}\right)$, and probing for expression of Musashi1 (Msi1) by in situ hybridization ( $\boldsymbol{C}$ ) indicates that the RMS in the Emx1-Cre/Pax6cKO cortex contains more progenitor/stem-like cells. $\boldsymbol{D}, \boldsymbol{H}, \boldsymbol{H}^{\prime}$, At the rostral-most levels, the enlarged GE makes ventricular protrusions that are heavily labeled by in situ probes for $\operatorname{Dlx} 1(\boldsymbol{D})$ and $\operatorname{Arx}\left(\boldsymbol{H}, \boldsymbol{H}^{\prime}\right)$, two markers for GABAergic interneurons. In $\boldsymbol{F}$, note that a portion of the accumulated progenitors at the pallial side of the PSPB are mitotically active, as indicated by labeling with the proliferative marker, Ki67, whereas the majority of accumulated cells at the PSPB are doublecortinpositive $(D c x)(\boldsymbol{E})$. G, A high-magnification image of $\mathrm{Dcx} / \mathrm{Ki} 67$ double staining shows a double-labeled cell with a DAPI overlay. $I, I^{\prime}$, The rostral cortex of Emx1-Cre/Pax6cKO mice is abundantly populated by GAD67 + interneurons. $J, J^{\prime}$, Immunostaining for GFAP reveals a severely diminished number of parenchymal astrocytes at the uppermost position of the neocortex (arrowhead) in the mutant compared with the control brain. In contrast, an excess of GFAP + astrocyte-like cells is seen in RMS (arrow). $\boldsymbol{K}, \boldsymbol{K}^{\prime}$, In situ hybridization analysis of Olig 1 expression reveals an enhanced signal in a band of cells below layer 1 (arrow) and within the CC (arrowhead) in the mutant. $L, L^{\prime}$, Cross sections from P10 control and mutant brains hybridized with an in situ probe for PLP/DM20illustrating that the thick GE at the PSPB and the neocortex contain an enhanced number of PLP/DM20+ oligodendrocytes in the Emx1-Cre/Pax6cKO mice. Scale bars: $\boldsymbol{E}, 200 \mu \mathrm{m} ; \boldsymbol{F}, \boldsymbol{J}^{\prime}$ (for $\left.\boldsymbol{J}, \boldsymbol{J}^{\prime}\right), 100 \mu \mathrm{m}$.

ing oligodendroglial cells (Deloulme et al., 2004; Hachem et al., 2005; Raponi et al., 2007). The Emx1-Cre/Pax6cKO cortex showed more $\mathrm{S} 100 \beta+/ \mathrm{BrdU}+$ cells at the uppermost position (378 \pm 52 cells $/ \mathrm{mm}^{2}$ ) compared with the control brains (133 \pm 41 cells $/ \mathrm{mm}^{2} ; p=0.0028 ; n=3$ mice/genotype) (data not shown), suggesting that, in the absence of Pax6, late RGs preferentially generate oligodendrocytes. In additional support of this conclusion, we found, in the GE at the PSPB and the cortical parenchyma of Emx1-Cre/Pax $6 c K O$ mice, an enlarged set of cells positive for PLP/DM20 (Fig. $6 L, L^{\prime}$ ). PLP/DM20 is a marker that faintly stains a second wave of distinct oligodendroglial lineage cells around E18.5 and increasingly after birth (Ivanova et al., 2003). Together, our findings indicate that, in the absence of Pax6 at the onset of cortical neurogenesis, the diminished pool of late RGPs fails to differentiate into SGL neuronal lineages beyond the immature neuron stage. Instead, the accumulated progenitors in 


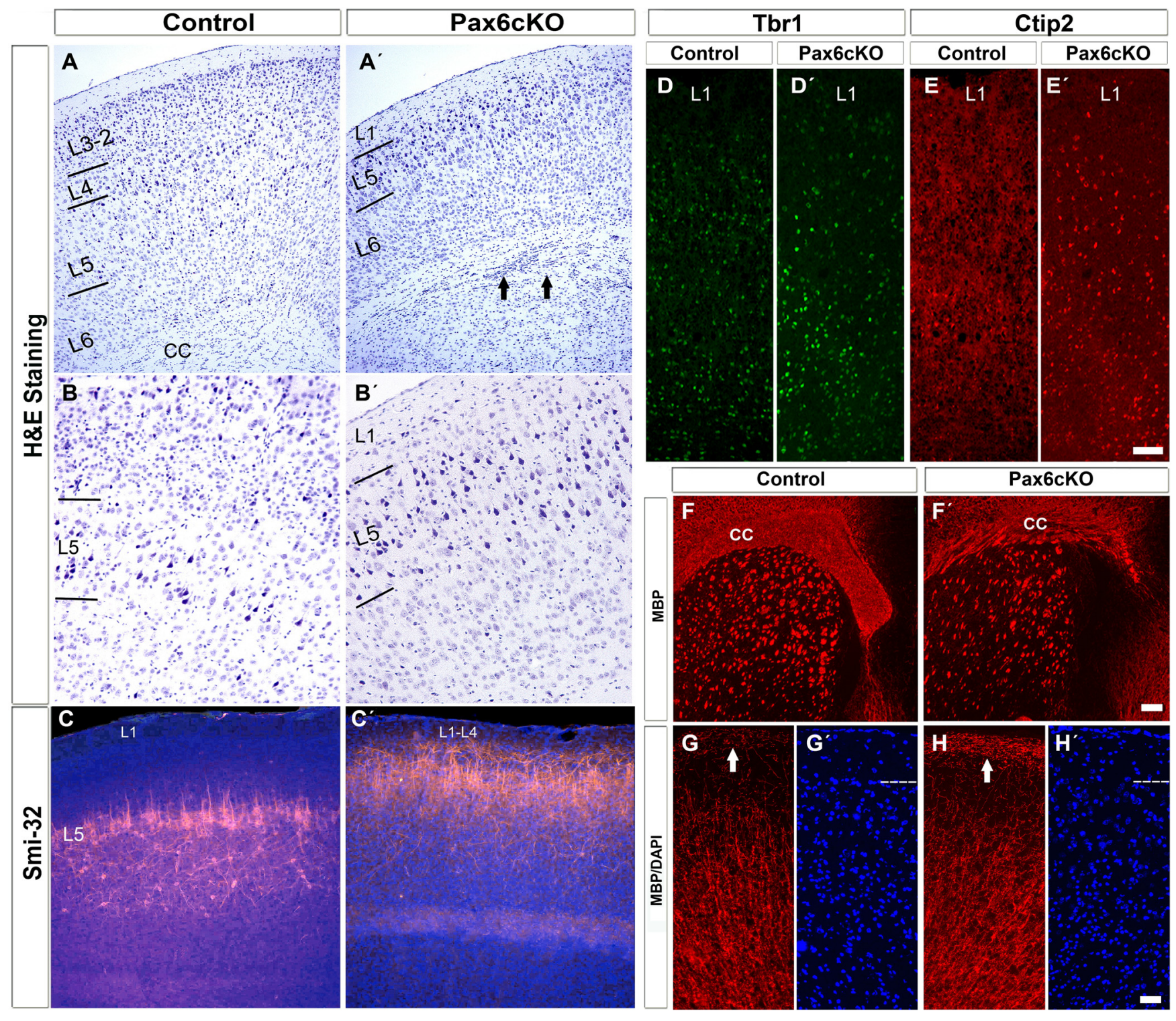

Figure 7. Cortical abnormalities in adult Emx1-Cre/Pax6cKO mice. $\boldsymbol{A}-\boldsymbol{H}^{\prime}$, Cross sections from brains of adult control and Emx1-Cre/Pax6cKO animals, 8 months (A-C') or 4, 5 months of age $\left(\boldsymbol{D}-\boldsymbol{H}^{\prime}\right)$, were examined after histological or immunohistochemical staining, as indicated. Micrographs in $\boldsymbol{A}-\boldsymbol{B}^{\prime}$ show that the superficial cortical layers (L4-L2) are almost completely missing in the adult Emx1-Cre/Paxc6KO neocortex. The arrows in $\boldsymbol{A}^{\prime}$ indicate cell aggregates within the corpus callosum. In $\boldsymbol{C}-\boldsymbol{E}^{\prime}$, note the ectopic superficial location of an enlarged set of pyramidal neurons, including Smi-32+ $\left(\boldsymbol{C}, \boldsymbol{C}^{\prime}\right), \operatorname{Tbr} 1+\left(\boldsymbol{D}, \boldsymbol{D}^{\prime}\right)$, and Ctip2 $+\left(\boldsymbol{E}, \boldsymbol{E}^{\prime}\right)$ subsets. $\boldsymbol{F}, \boldsymbol{F}^{\prime}$, Immunostaining for MBP antibody shows that C( is not compact in the mutant brain. $\boldsymbol{G}^{\prime}, \boldsymbol{H}^{\prime}$, The mutant cortex contains more densely packed DAPI+ cells at position of L1 (depicted by a line), which showed intensive immunostaining for MBP antibody (G, $\boldsymbol{H}$, arrows). Scale bars: (in $\left.\boldsymbol{E}^{\prime}, \boldsymbol{H}^{\prime}\right) \mathbf{D}-\boldsymbol{E}^{\prime}, \mathbf{G}-\boldsymbol{H}^{\prime}, 50 \mu \mathrm{m}$; (in $\boldsymbol{F}^{\prime}$ ) $F, F^{\prime}, 200 \mu \mathrm{m}$.

the pallial GE seem to produce, even at postnatal stages, an excess of interneurons and oligodendrocytes.

\section{Morphological disturbances in the cortex of the mature Emx1-Cre/Pax6cKO mice}

We next investigated whether the layer-specific abnormalities detected in juvenile Emx1-Cre/Pax6cKO mice are preserved in the adult (3 months of age) cortex. Consistent with the observed abnormalities at P10, the SGLs were severely attenuated at all rostrocaudal levels of the adult mutant brain, but were much more severely affected rostrally (Fig. $7 A, A^{\prime}, B, B^{\prime}$ ). At a superficial location, the cortex of adult Emxl-Cre/Pax6cKO mice contained an enlarged population of Tbr1+ and Ctip2+ IGL neurons with the appearance of big pyramidal neurons (Fig. $\left.7 D, D^{\prime}, E, E^{\prime}\right)$. In addition, labeling for the neurofilament, Smi-
32, revealed extensive branching of the apical dendrites of these pyramidal neurons (Fig. 7C, $C^{\prime}$ ).

Consistent with the severe underrepresentation of SGLs, which contribute mostly to the interhemispheric connections, the corpus callosum (CC) of the mutant was underdeveloped, with loosely distributed $\mathrm{MBP}+$ myelinated fibers (Fig. $7 F, F^{\prime}$ ) and incorporated cells ( $A, A^{\prime}$, arrows). The fronto-orbital cortical GE exhibited an abundant accumulation of small, dark cells (data not shown). Interestingly, the hippocampus of the mutant appeared enlarged, with a thicker pyramidal layer (supplemental Fig. $7 A, A^{\prime}, B, B^{\prime}$, available at www.jneurosci.org as supplemental material), and the pPV above the hippocampus contained a dense population of pyramidal-like cells that seemed to migrate toward the CA1 region (supplemental Fig. $7 B^{\prime}$, arrows, available at www. jneurosci.org as supplemental material). In addition, a number of 
cell aggregates located above the hippocampus were $\mathrm{GAD}+$ and established synaptic contacts with the CA1 region of the hippocampus (supplemental Fig. $7 D-G$, available at www.jneurosci.org as supplemental material).

Because the Cre activity driven by the Emx1-Cre line extends to later developmental stages in some progenitors of the lateral and ventral pallium (Gorski et al., 2002), we studied the specification of the main amygdala nuclei. Judging from the pattern of Lmo3 and Clim $1 a$ expression in the lateral and basolateral nucleus, which was indistinguishable in animals of both genotypes, these amygdalar components appeared to be mostly normal in adult Emx1-Cre/Pax6cKO brains (supplemental Fig. $7 I, I^{\prime}, J, J$, available at www.jneurosci. org as supplemental material). However, the pyriform cortex in the mutant brain was severely underdeveloped (supplemental Fig. $7 H, H^{\prime}, J, J^{\prime}$, available at www. jneurosci.org as supplemental material).

Emx1-Cre/Pax6cKO mice are impaired in behavioral tasks that require sensory-motor integration

Intrigued by the nearly complete absence of neurons of the upper-cortical layers in Emx1-Cre/Pax6cKO mice, we examined the behavioral phenotype of 6-month-old mutants and littermate controls. Despite the severe brain morphology disturbances, the overt behavior of Pax $6 c K O$ mice was indistinguishable from that of control mice in the home cage. Emx1-Cre/Pax6cKO mice also had normal body weights and exhibited no gross abnormalities in preliminary tests of muscle strength, vision, and hearing (data not shown).

Behavioral differences were noted, however, when the mice were tested for specific behavioral tasks. Emx1-Cre/Pax6cKO mice demonstrated a decreased locomotor activity in the openfield exploration test (Crawley, 1999), traveling a significantly smaller distance than control animals $(p<0.05)$ (Fig. $8 A$ ). The time spent in the central and peripheral zone of the open field by the two groups was equivalent, suggesting that the Emx1-Cre/ Pax6cKO mice have normal exploratory behavior, with no change in fear- or anxiety-related behavior. We also used the elevated plus maze, an additional test of anxiety that is based on the conflict between the desire to explore a novel environment and the aversion to a brightly lit, open space (Pellow et al., 1985; Lister, 1987). Both Emxl-Cre/Pax6cKO and control mice explored the open arms equally in these assays (Fig. $8 B$ ). Because we did not detect differences in anxiety between $\mathrm{Pax} 6 \mathrm{cKO}$ mice and controls, we concluded that the observed decrease in the locomotor activity would be a consequence of a deficiency in the motor performance. Indeed, mutant mice showed a significantly shorter latency-to-fall in the rotarod test $(p<0.05)$ (Fig. $8 C$ ), indicating a motor balance and/or coordination deficit.

We next used the hot-plate test to evaluate sensorimotor in-
B

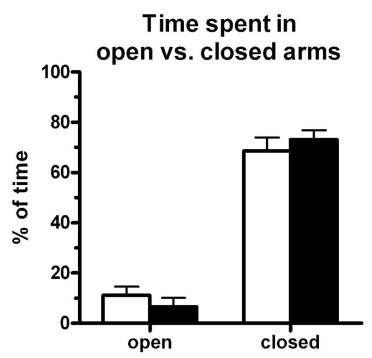

E
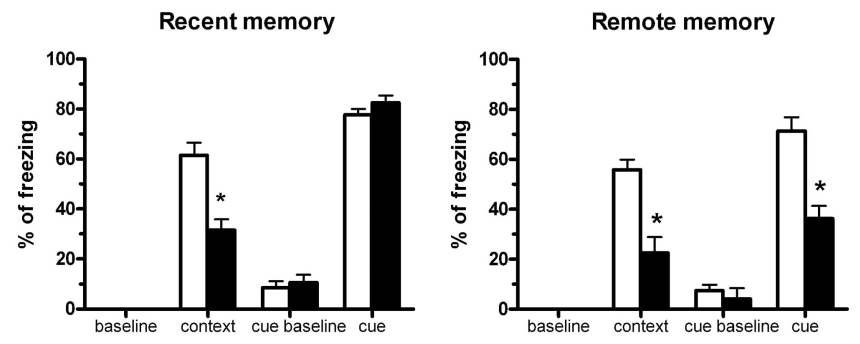

H

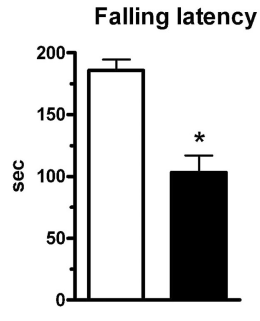

$\mathbf{F}$

Figure 8. Alterations in behavior and cognitive functions of adult Emx1-Cre/Pax6cKO mice. $\boldsymbol{A}$, Total distance traveled in the

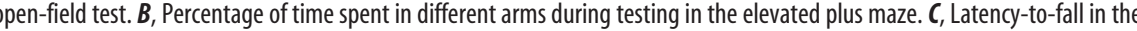
Time course of extinction of the learned fear in cued-fear conditioning task. $\boldsymbol{H}$, Prepulse inhibition of the startle response. All results are presented as means \pm SEM. ${ }^{*} p<0.05$, Kruskal-Wallis ANOVA.

tegration at the cortical level (Pastoriza et al., 1996). In this test, which is frequently used to measure pain thresholds, the mouse is placed on hot surface and the latency of the defensive response (i.e., jumping or licking of the hindpaw) is measured. Emx1-Cre/ Pax6cKO mice showed a significantly slower defensive behavior response compared with littermate controls $(p<0.05)$ (Fig. $8 D$ ). Responses to the tail flick test, which measures pain sensitivity at the level of spinal cord nociception and does not require the cerebral cortex, were similar in both mutant mice and littermate controls (data not shown).

Together, these findings indicate that Emx1-Cre/Pax6cKO mice have a cortical-level deficit in the integration of sensory and motor information.

\section{Impairment of conditioned-fear memory in Emx1Cre-Pax6cKO mice}

The profound architectural defects in the cortex and hippocampus of Emx1-Cre/Pax $6 c K O$ mice implicated the possibility of defects in memory formation. After applying several experimental paradigms, we found that mutant mice showed impaired performances of different types of conditioned-fear memory. In one type of such tests, the animals have to learn to associate a defined 
context with an electroshock through contextual fear conditioning. When placed back in the same context, the rodents react by freezing, even in the absence of an aversive stimulus (Fanselow, 2000). When tested $24 \mathrm{~h}$ after the conditioning, the Pax6cKO mice showed a significant reduction in the freezing behavior (Fig. $8 E)(p<0.05)$, indicating a deficit in the recent memory of the learned association. Contextual fear conditioning is dependent on the function of both the amygdala and the hippocampus (Phillips and LeDoux, 1992). To investigate whether these structures were differentially involved in the observed recent-memory deficits in the mutants, we used hippocampus-independent auditory-cue conditioning. In this test, the animals learn to associate a conditioned stimulus (tone) with an aversive unconditioned stimulus (electroshock), thus enabling amygdaladependent fear response to be elicited by exposure to the conditioned stimulus only. We found no differences in the freezing behavior after presentation of the conditioned stimulus between the Pax6cKO mice and controls (Fig. 8E), indicating that the observed contextual recent-memory deficit does not depends on amygdala function, but involves a dysfunction of hippocampus. Given the severe malformation of the cortex of the mutant cortex, we tested the Emx1-Cre/Pax6cKO mice for remote memory recall $31 \mathrm{~d}$ after the conditioning, a capability that depends on the structural integrity of the cortex (Frankland et al., 2004). Notably, the Emx1-Cre/Pax6cKO mutant mice exhibited a significantly lower level of freezing behavior with both context and auditory-cue conditioning $(p<0.05)$ (Fig. $8 F)$.

\section{Pax 6 KKO mice show a diminished performance in prefrontal cortex-dependent behavioral tasks}

The extinction of the conditioned-fear memory depends on an intact prefrontal cortex (Quirk et al., 2006). Considering the diverse morphological defects of the prefrontal/frontal cortex of the Emx1-Cre/Pax6cKO mice, we expected that these mice would exhibit deficits in tasks for extinction of conditioned-cued memory. This behavior manifests as a reduction in the freezing response after repeated exposure to the conditioned stimulus (tone) alone. Mutants exhibited a significantly slower extinction of conditioned-fear memory than did control mice $(p<0.05)$ (Fig. 8G).

Prepulse inhibition of the startle response characterizes sensorimotor gating, which is another form of behavior that requires intact prefrontal cortex function (for review, see Koch and Segev, 2000). However, measurement of prepulse inhibition revealed no significant differences between Emx1-Cre/Pax $6 c \mathrm{KO}$ and control animals $(p>0.05)$ (Fig. $8 H$ ), indicating that only selected prefrontal cortex-dependent behaviors are disturbed in Pax6cKO mice.

Together, these series of experiments indicate that ablation of Pax6 function at the onset of cortical neurogenesis causes deficits in prefrontal cortex-dependent sensorimotor integration and extinction of memory, hippocampal-dependent short-term contextual memory, and neocortex-dependent remote memory recall. Thus, the developmental regulator Pax6 plays a role in establishing cortical circuits that underlie behavioral and cognitive functions.

\section{Discussion}

\section{Pax6 controls distinct neural subprograms during corticogenesis}

Here, we provided new as well as conclusive supporting evidence indicating that Pax6-dependent mechanisms control the genera- tion of distinct neural sublineages of the MZ, IGLs, and SGLs in the developing cortex and possibly after birth.

In the absence of Pax6, the number of Reelin+/Calretinin+ cells in the MZ of Sey/Sey mutant progressively increases during embryogenesis based on a non-cell-autonomous mechanism that appears to include migration of Reelin- and Calretinin-positive cells accumulated in the OB remnants located in the lateral telencephalon (Jiménez et al., 2000; Stoykova et al., 2003). Because the Emx1-Cre line does not drive inactivation of the early expression of Pax6 in the olfactory placode, Emx1-Cre/Pax6cKO mice have differentiated OBs at a normal location. Despite this, the number of Reelin + , Calretinin + , and Tbr1+ cells in MZ was significantly augmented in these mutants. Several lines of evidence indicated the existence of a common progenitor pool in cortical VZ, capable of generating neurons of both Reelin + CR and early-born neuronal lineages of the CP. Thus, expression of the transcription factor, Foxg1, stimulates RG cells to acquire a Reelin + CR fate while suppressing the production of CP neurons (Hanashima et al., 2004). Notably, Reelin + CR cells are descendents of the Emx1-Cre progenitor lineage (Gorski et al., 2002), and clones of early (E10-E11) cortical progenitors contained both Reelin + CR and IGL neuronal sets, including the Er81+ L5 neuronal lineage (Shen et al., 2006). Together with the observation that Er81 is a direct downstream target of Pax6 (Tuoc and Stoykova, 2008a), these findings strongly suggest that Pax6 might intrinsically regulate the neuronal subtype that arises from the Reelin+/Er81+ lineage of the developing cortex.

During cortical neurogenesis, Pax6 is expressed at high and low level in the early and late RG progenitors, respectively (Tuoc and Stoykova, 2008b), showing a rostrolateral-high to caudomedial-low gradient. Here, we provided novel evidence indicating that generation of SGL neurons is severely affected only if Pax6 is inactivated at the onset of corticogenesis (Emx1-Crel Pax6cKO mice), whereas later inactivation of Pax6 ( $h$ GFAP-Cre/ Pax6cKO mice) does not affect the specification or the number of SGL neurons, suggesting that cortical progenitors at different stages have different requirements for Pax6. In this line of evidence, previous data indicated that overexpression of Pax6 in vivo affected the RG proliferation and caused progenitor apoptosis only during early neurogenesis (Berger et al., 2007). Notably, the expansion of IGLs and the reduction of SGL neuronal sets observed in Emx1-Cre/Pax6cKO mice was predominant in the rostral cortex, which correlates with a severe diminishing of the motor area size in these mutants (Piñon et al., 2008). We propose, therefore, that Pax6 deficiency, with failure in progenitor cell cycle progression at the onset of cortical neurogenesis, causes both laminar and area disturbances of the mature rostral cortex.

It is well known that cortical neurons in the mouse are generated over 11 cell cycles during the period E11-E17 (Takahashi et al., 1999). Initially, symmetric divisions of early RGs lead to the expansion of the early progenitor pool (Rakic, 1988). The neuronal diversity of cortical layers arises from sequential apical asymmetric differentiative divisions of Pax6 + RG cells (McConnell, 1985, 1988; Walsh and Cepko, 1988), whereas symmetric division of intermediate progenitors in the SVZ and basal VZ multiplies the generated temporal neuronal identities (Kriegstein et al., 2006; Kowalczyk et al., 2009). The role of Pax6 in direct versus indirect (through IPs) neuronogenesis in the developing cortex is still not clear. Emx1-Cre-mediated Pax6 inactivation starting at E9.5 (Gorski et al., 2002) did not affect the molecular specification of IGL subtypes, except for the Er81+ L5 neurons, but it caused an increase in at least six IGL neuronal sets: Tbr1+ L6, Ctip2 + L5, Fezl+ L5, Clim1a+ L5, Lmo4+ L5, and Id2+ L5. 
Premature exit from mitotic cycle and differentiation of Pax6 $6^{-1-}$ progenitors has been reported for $\mathrm{Pax6}^{+/+} / \mathrm{Pax}^{-/-}$chimeric mice (Quinn et al., 2007) and Small eye mice (Estivill-Torrus et al., 2002). In agreement with these findings, we show that the CP of Emx1-Cre/Pax $6 c \mathrm{KO}$ mice at E15.5 contained an increased number of early-born Tbr1+IGL neurons and a greater proportion of heavily BrdU-labeled cells, suggesting that the Pax6deficient cells prematurely exit the cell cycle and differentiate. One possibility could be that, in Pax6 deficiency, the early RG progenitors terminally differentiate after initial asymmetric division and prematurely exit from mitotic cycle without generating IPs (direct neuronogenesis). Notably, however, an increased mitotic activity has been observed abventricularly (in a position where IPs normally divide) in Emx1-Cre/Pax6cKO mice (this study) and Pax6-deficient embryos (Götz et al., 1998; Haubst et al., 2004; Quinn et al., 2007). The proliferation of IPs in the SVZ is negatively controlled by the transcription factor Cux2, whose expression is completely abolished in Pax6 LOF mutants (Nieto et al., 2004; Zimmer et al., 2004; this study). It is possible therefore that, in Pax6 deficiency, the IPs undergo a greater than normal number of symmetric divisions abventricularly (indirect neuronogenesis), thus increasing the size of the earlier-generated IGL neuronal identities. Although additional research is needed to address the Pax6 contribution to direct versus indirect neuronogenesis, the data from our group and others suggest that, by controlling mitotic cycle progression during early corticogenesis, Pax6 plays an essential role in the establishment of neuronal layer identities in the MZ, IGLs, and SGLs.

As related to glial differentiation, we show that cortical parenchymal astrocytes are underrepresented in Emx1-Cre/Pax6cKO mice, but the mutant cortex contains an increased amount of Olig1 + and PLP/D20 + oligodendroglial cells, the later glial subset produced mainly by prenatal and postnatal RG cells (Ivanova et al., 2003). The enhanced oligodendroglial cell numbers in mutant cortex were supported by two additional markers: $S 100 \beta$ in early postnatal brain and MBP in adult brain. Thus, although Pax6 is apparently not involved in the specification of upper neuronal cell fate, the late prenatal and juvenile RG progenitors, expressing Pax6 at low levels, appear to play a role in the specification of astroglial (Sakurai and Osumi, 2008) and oligodendroglial cell lineages, possibly even after birth.

\section{Pax6 deficiency during corticogenesis leads to cognitive disabilities at maturity}

The behavioral and anatomical disturbances in the adult Emx1Cre/Pax6cKO mice resemble the cognitive disabilities and structural abnormalities observed in aniridia patients, heterozygous to PAX6 mutations. The most important cognitive deficit of aniridia patients is related to impairment of the frontal lobe development (Heyman et al., 1999; Malandrini et al., 2001; Ellison-Wright et al., 2004). Aniridia probands show a deficiency in verbal tests that requires an active inhibition controlled by the prefrontal cortex (Heyman et al., 1999; Thompson et al., 2004; Bamiou et al., 2007a). Similarly, Emx1-Cre/Pax6cKO mice demonstrated a deficit in a test for extinction of cued-fear conditioning that depends on an intact prefrontal cortex (Quirk et al., 2006). As shown previously, the size of motor areas in juvenile Emx1-Cre/ Pax6cKO mice (Piñon et al., 2008) and the thickness of the frontal and fronto-orbital cortices of adult mutants (Boretius et al., 2009) were severely reduced, an effect that could be mainly attributed to the almost complete loss of upper cortical layers. The SGL neurons are the main contributors to the CC, which is the largest fiber bundle that connects the two hemispheres and is severely malformed in Emx1-Cre/Pax6cKO mice (Boretius et al., 2009; this study). These findings are in line with magnetic resonance imaging (MRI) data for aniridia patients showing a dysgenesis of CC, an absence or hypoplasia of the anterior commissure, and a reduction in prefrontal gray matter (Sisodiya et al., 2001; Ellison-Wright et al., 2004; Bamiou et al., 2007b). We found that Emx1-Cre/Pax6cKO mice have a deficit in motor balance and coordination on the rotarod test, and in avoidance behavior in the hot-plate test, two behavioral paradigms assumed to reflect the integration of sensory information controlling specific motor response (Pastoriza et al., 1996). This deficiency could be related to both the shrunken size of motor areas and the failure to establish correct interhemispheric connections between motor representations through the CC (Schieppati et al., 1984; Stancak et al., 2002). In addition to malformed SGLs, the cortex of adult Emx1-Cre/Pax6cKO mice contained an enlarged set of GABAergic interneurons. The SGL neurons use the excitatory transmitter, glutamate, and provide excitatory synaptic effects, whereas GABAergic INs, which are also activated by the excitatory transcallosal fibers, mediate interhemispheric inhibition (Conti and Manzoni, 1994). Together, these findings suggest that, in Pax6 deficiency, dysgenesis of SGLs and the presence of ectopic INs cause a profound deficit in the establishment of the sensorimotor integration.

The Emx1-Cre/Pax6cKO mice exhibited a deficit for the recall of hippocampal-dependent recent memory, as evidenced in a test for contextual fear conditioning. The presence of a surplus of Vglut1+, NSE+ pyramidal neurons in CA1-CA3 regions of the hippocampus was shown in the juvenile Emx1-Cre/Pax6cKO mice and an increased compactness of the Ammon's horn was evident in the adult mutants. Notably, however, recent results from manganese-induced MRI signal enhancement analysis suggest that the pyramidal cells in Pax6cKO mice function normally (Boretius et al., 2009). These findings are in agreement with MRI results for aniridia patients, who show learning disabilities (Heyman et al., 1999; Malandrini et al., 2001) and exhibit local excesses of gray-matter volume in the hippocampus and occipital cortex, areas that are usually activated by verbal executive tasks (Ellison-Wright et al., 2004). It is worth noting that the septohippocampal connections were severely disorganized in Emx1Cre/Pax6cKO mice and showed a decreased manganese-induced MRI signal enhancement, implying a functional deficit (Boretius at al., 2009). We therefore assume that the hippocampusdependent memory deficit in Emx1-Cre/Pax6cKO mice also includes abnormal septo-hippocampal connectivity (Boretius et al., 2009).

The Emx1-Cre/Pax6cKO mice exerted a selective deficiency in remote-cued fear memory recall. Remarkably, the neurons of the IGLs and SGLs appear to be selectively activated in the process of memory consolidation: whereas IGLs are activated mainly when recent memory is tested, predominantly L3-L2 neurons are activated during remote memory recall (Frankland et al., 2004). Storage of longer-term memories is dependent on the function of intact neocortical circuits, and consolidation of short-term memories involves a change in the strength of the corticocortical connection (Müller and Pilzecker, 1900; Miller, 1996; Dudai, 2004; Maviel et al., 2004). We therefore propose that the absence of Pax6 during development causes the profound defects on the cortical layering and intercortical and intracortical connectivity (Boretius et al., 2009) that underlie cognitive disabilities after birth in mouse, and possibly in humans. Additional experiments are in progress to explore more directly the relationship between 
the observed morphological disruptions and behavioral disabilities at a physiological level.

\section{References}

Alcamo EA, Chirivella L, Dautzenberg M, Dobreva G, Fariñas I, Grosschedl R, McConnell SK (2008) Satb2 regulates callosal projection neuron identity in the developing cerebral cortex. Neuron 57:364-377.

Arlotta P, Molyneaux BJ, Chen J, Inoue J, Kominami R, Macklis JD (2005) Neuronal subtype-specific genes that control corticospinal motor neuron development in vivo. Neuron 45:207-221.

Ashery-Padan R, Marquardt T, Zhou X, Gruss P (2000) Pax6 activity in the lens primordium is required for lens formation and for correct placement of a single retina in the eye. Genes Dev 14:2701-2711.

Bamiou DE, Campbell NG, Musiek FE, Taylor R, Chong WK, Moore A, van Heyningen V, Free S, Sisodiya S, Luxon LM (2007a) Auditory and verbal working memory deficits in a child with congenital aniridia due to a PAX6 mutation. Int J Audiol 46:196-202.

Bamiou DE, Free SL, Sisodiya SM, Chong WK, Musiek F, Williamson KA, van Heyningen V, Moore AT, Gadian D, Luxon LM (2007b) Auditory interhemispheric transfer deficits, hearing difficulties, and brain magnetic resonance imaging abnormalities in children with congenital aniridia due to PAX6 mutations. Arch Pediatr Adolesc Med 161:463-469.

Bayer SA, Altman J, Russo RJ, Dai XF, Simmons JA (1991) Cell migration in the rat embryonic neocortex. J Comp Neurol 307:499-516.

Berger J, Berger S, Tuoc TC, D’Amelio M, Cecconi F, Gorski JA, Jones KR, Gruss P, Stoykova A (2007) Conditional activation of Pax6 in the developing cortex of transgenic mice causes progenitor apoptosis. Development 134:1311-1322.

Bishop KM, Goudreau G, O'Leary DD (2000) Regulation of area identity in the mammalian neocortex by Emx2 and Pax6. Science 288:344-349.

Boretius S, Michaelis T, Tammer R, Ashery-Padan R, Frahm J, Stoykova A (2009) In vivo MRI of altered brain anatomy and fiber connectivity in adult Pax6 deficient mice. Cereb Cortex 27:27.

Britanova O, de Juan Romero C, Cheung A, Kwan KY, Schwark M, Gyorgy A, Vogel T, Akopov S, Mitkovski M, Agoston D, Sestan N, Molnár Z, Tarabykin V (2008) Satb2 is a postmitotic determinant for upper-layer neuron specification in the neocortex. Neuron 57:378-392.

Bulchand S, Subramanian L, Tole S (2003) Dynamic spatiotemporal expression of LIM genes and cofactors in the embryonic and postnatal cerebral cortex. Dev Dyn 226:460-469.

Bulfone A, Martinez S, Marigo V, Campanella M, Basile A, Quaderi N, Gattuso C, Rubenstein JL, Ballabio A (1999) Expression pattern of the Tbr2 (Eomesodermin) gene during mouse and chick brain development. Mech Dev 84:133-138.

Carić D, Gooday D, Hill RE, McConnell SK, Price DJ (1997) Determination of the migratory capacity of embryonic cortical cells lacking the transcription factor Pax-6. Development 124:5087-5096.

Caviness VS Jr, Goto T, Tarui T, Takahashi T, Bhide PG, Nowakowski RS (2003) Cell output, cell cycle duration and neuronal specification: a model of integrated mechanisms of the neocortical proliferative process. Cereb Cortex 13:592-598.

Choi BH (1988) Prenatal gliogenesis in the developing cerebrum of the mouse. Glia 1:308-316.

Conti F, Manzoni T (1994) The neurotransmitters and postsynaptic actions of callosally projecting neurons. Behav Brain Res 64:37-53.

Crawley JN (1999) Behavioral phenotyping of transgenic and knockout mice: experimental design and evaluation of general health, sensory functions, motor abilities, and specific behavioral tests. Brain Res 835:18-26.

Cubelos B, Sebastián-Serrano A, Kim S, Moreno-Ortiz C, Redondo JM, Walsh CA, Nieto M (2008) Cux-2 controls the proliferation of neuronal intermediate precursors of the cortical subventricular zone. Cereb Cortex 18:1758-1770.

Davidoff M, Schulze W (1990) Combination of the peroxidase antiperoxidase (PAP)- and avidin-biotin-peroxidase complex (ABC)-techniques: an amplification alternative in immunocytochemical staining. Histochemistry 93:531-536.

Dehay C, Kennedy H (2007) Cell-cycle control and cortical development. Nat Rev Neurosci 8:438-450.

Deloulme JC, Raponi E, Gentil BJ, Bertacchi N, Marks A, Labourdette G, Baudier J (2004) Nuclear expression of S100B in oligodendrocyte progenitor cells correlates with differentiation toward the oligodendroglial lineage and modulates oligodendrocytes maturation. Mol Cell Neurosci 27:453-465.

Doetsch F, Caillé I, Lim DA, García-Verdugo JM, Alvarez-Buylla A (1999) Subventricular zone astrocytes are neural stem cells in the adult mammalian brain. Cell 97:703-716.

Dudai Y (2004) The neurobiology of consolidations, or, how stable is the engram? Annu Rev Psychol 55:51-86.

Ellison-Wright Z, Heyman I, Frampton I, Rubia K, Chitnis X, Ellison-Wright I, Williams SC, Suckling J, Simmons A, Bullmore E (2004) Heterozygous PAX6 mutation, adult brain structure and fronto-striato-thalamic function in a human family. Eur J Neurosci 19:1505-1512.

Estivill-Torrus G, Pearson H, van Heyningen V, Price DJ, Rashbass P (2002) Pax6 is required to regulate the cell cycle and the rate of progression from symmetrical to asymmetrical division in mammalian cortical progenitors. Development 129:455-466.

Fanselow MS (2000) Contextual fear, gestalt memories, and the hippocampus. Behav Brain Res 110:73-81.

Frankland PW, Bontempi B, Talton LE, Kaczmarek L, Silva AJ (2004) The involvement of the anterior cingulate cortex in remote contextual fear memory. Science 304:881-883.

Gorski JA, Talley T, Qiu M, Puelles L, Rubenstein JL, Jones KR (2002) Cortical excitatory neurons and glia, but not GABAergic neurons, are produced in the Emx1-expressing lineage. J Neurosci 22:6309-6314.

Götz M, Stoykova A, Gruss P (1998) Pax6 controls radial glia differentiation in the cerebral cortex. Neuron 21:1031-1044.

Guillemot F, Molnár Z, Tarabykin V, Stoykova A (2006) Molecular mechanisms of cortical differentiation. Eur J Neurosci 23:857-868.

Hachem S, Aguirre A, Vives V, Marks A, Gallo V, Legraverend C (2005) Spatial and temporal expression of S100B in cells of oligodendrocyte lineage. Glia 51:81-97.

Hanashima C, Li SC, Shen L, Lai E, Fishell G (2004) Foxg1 suppresses early cortical cell fate. Science 303:56-59.

Haubensak W, Attardo A, Denk W, Huttner WB (2004) Neurons arise in the basal neuroepithelium of the early mammalian telencephalon: a major site of neurogenesis. Proc Natl Acad Sci U S A 101:3196-3201.

Haubst N, Berger J, Radjendirane V, Graw J, Favor J, Saunders GF, Stoykova A, Götz M (2004) Molecular dissection of Pax6 function: the specific roles of the paired domain and homeodomain in brain development. Development 131:6131-6140.

Heins N, Malatesta P, Cecconi F, Nakafuku M, Tucker KL, Hack MA, Chapouton P, Barde YA, Götz M (2002) Glial cells generate neurons: the role of the transcription factor Pax6. Nat Neurosci 5:308-315.

Hevner RF, Daza RA, Rubenstein JL, Stunnenberg H, Olavarria JF, Englund C (2003a) Beyond laminar fate: toward a molecular classification of cortical projection/pyramidal neurons. Dev Neurosci 25:139-151.

Hevner RF, Neogi T, Englund C, Daza RA, Fink A (2003b) Cajal-Retzius cells in the mouse: transcription factors, neurotransmitters, and birthdays suggest a pallial origin. Brain Res Dev Brain Res 141:39-53.

Heyman I, Frampton I, van Heyningen V, Hanson I, Teague P, Taylor A, Simonoff E (1999) Psychiatric disorder and cognitive function in a family with an inherited novel mutation of the developmental control gene PAX6. Psychiatr Genet 9:85-90.

Ivanova A, Nakahira E, Kagawa T, Oba A, Wada T, Takebayashi H, Spassky N, Levine J, Zalc B, Ikenaka K (2003) Evidence for a second wave of oligodendrogenesis in the postnatal cerebral cortex of the mouse. J Neurosci Res 73:581-592.

Jiménez D, García C, de Castro F, Chédotal A, Sotelo C, de Carlos JA, Valverde F, López-Mascaraque L (2000) Evidence for intrinsic development of olfactory structures in Pax-6 mutant mice. J Comp Neurol 428:511-526.

Jones L, López-Bendito G, Gruss P, Stoykova A, Molnár Z (2002) Pax6 is required for the normal development of the forebrain axonal connections. Development 129:5041-5052.

Koch C, Segev I (2000) The role of single neurons in information processing. Nat Neurosci 3 [Suppl]:1171-1177.

Kowalczyk T, Pontious A, Englund C, Daza RA, Bedogni F, Hodge R, Attardo A, Bell C, Huttner WB, Hevner RF (2009) Intermediate neuronal progenitors (basal progenitors) produce pyramidal-projection neurons for all layers of cerebral cortex. Cereb Cortex 23:23.

Kriegstein A, Noctor S, Martínez-Cerdeño V (2006) Patterns of neural stem and progenitor cell division may underlie evolutionary cortical expansion. Nat Rev Neurosci 7:883-890. 
Kroll TT, O'Leary DD (2005) Ventralized dorsal telencephalic progenitors in Pax6 mutant mice generate GABA interneurons of a lateral ganglionic eminence fate. Proc Natl Acad Sci U S A 102:7374-7379.

Levers TE, Edgar JM, Price DJ (2001) The fates of cells generated at the end of neurogenesis in developing mouse cortex. J Neurobiol 48:265-277.

Li HS, Wang D, Shen Q, Schonemann MD, Gorski JA, Jones KR, Temple S, Jan LY, Jan YN (2003) Inactivation of Numb and Numblike in embryonic dorsal forebrain impairs neurogenesis and disrupts cortical morphogenesis. Neuron 40:1105-1118.

Lister RG (1987) The use of a plus-maze to measure anxiety in the mouse. Psychopharmacology (Berl) 92:180-185.

Lukaszewicz A, Savatier P, Cortay V, Giroud P, Huissoud C, Berland M, Kennedy H, Dehay C (2005) G1 phase regulation, area-specific cell cycle control, and cytoarchitectonics in the primate cortex. Neuron 47:353-364.

Malandrini A, Mari F, Palmeri S, Gambelli S, Berti G, Bruttini M, Bardelli AM, Williamson K, van Heyningen V, Renieri A (2001) PAX6 mutation in a family with aniridia, congenital ptosis, and mental retardation. Clin Genet 60:151-154.

Malatesta P, Hack MA, Hartfuss E, Kettenmann H, Klinkert W, Kirchhoff F, Götz M (2003) Neuronal or glial progeny: regional differences in radial glia fate. Neuron 37:751-764.

Maviel T, Durkin TP, Menzaghi F, Bontempi B (2004) Sites of neocortical reorganization critical for remote spatial memory. Science 305:96-99.

McConnell SK (1985) Migration and differentiation of cerebral cortical neurons after transplantation into the brains of ferrets. Science 229:1268-1271.

McConnell SK (1988) Development and decision-making in the mammalian cerebral cortex. Brain Res 472:1-23.

McConnell SK, Kaznowski CE (1991) Cell cycle dependence of laminar determination in developing neocortex. Science 254:282-285.

Miller R (1996) Cortico-thalamic interplay and the security of operation of neural assemblies and temporal chains in the cerebral cortex. Biol Cybern 75:263-275.

Miyata T, Kawaguchi A, Saito K, Kawano M, Muto T, Ogawa M (2004) Asymmetric production of surface-dividing and non-surface-dividing cortical progenitor cells. Development 131:3133-3145.

Molyneaux BJ, Arlotta P, Hirata T, Hibi M, Macklis JD (2005) Fezl is required for the birth and specification of corticospinal motor neurons. Neuron 47:817-831.

Moorman AF, Houweling AC, de Boer PA, Christoffels VM (2001) Sensitive nonradioactive detection of mRNA in tissue sections: novel application of the whole-mount in situ hybridization protocol. J Histochem Cytochem 49:1-8.

Müller GE, Pilzecker A (1900) Experimentelle Beiträge zur Lehre vom Gedächtnis. Psychol Ergänzungsband 1:1-300.

Muzio L, DiBenedetto B, Stoykova A, Boncinelli E, Gruss P, Mallamaci A (2002) Conversion of cerebral cortex into basal ganglia in $E m \times 2^{-1}$ - Pax6 $^{\text {Sey/Sey }}$ double-mutant mice. Nat Neurosci 5:737-745.

Nakagawa Y, Johnson JE, O'Leary DD (1999) Graded and areal expression patterns of regulatory genes and cadherins in embryonic neocortex independent of thalamocortical input. J Neurosci 19:10877-10885.

Nieto M, Monuki ES, Tang H, Imitola J, Haubst N, Khoury SJ, Cunningham J, Gotz M, Walsh CA (2004) Expression of Cux-1 and Cux-2 in the subventricular zone and upper layers II-IV of the cerebral cortex. J Comp Neurol 479:168-180.

Nishiyama A, Lin XH, Giese N, Heldin CH, Stallcup WB (1996) Colocalization of NG2 proteoglycan and PDGF alpha-receptor on O2A progenitor cells in the developing rat brain. J Neurosci Res 43:299-314.

Noctor SC, Martínez-Cerdeño V, Ivic L, Kriegstein AR (2004) Cortical neurons arise in symmetric and asymmetric division zones and migrate through specific phases. Nat Neurosci 7:136-144.

O’Leary DD, Nakagawa Y (2002) Patterning centers, regulatory genes and extrinsic mechanisms controlling arealization of the neocortex. Curr Opin Neurobiol 12:14-25.

Pastoriza LN, Morrow TJ, Casey KL (1996) Medial frontal cortex lesions selectively attenuate the hot plate response: possible nocifensive apraxia in the rat. Pain 64:11-17.

Pellow S, Chopin P, File SE, Briley M (1985) Validation of open:closed arm entries in an elevated plus-maze as a measure of anxiety in the rat. J Neurosci Methods 14:149-167.

Peters A, Jones EG, eds (1985) Cerebral cortex, Vol. 3, Visual cortex; Vol. 4, Association and auditory cortices. New York, London: Plenum.
Phillips RG, LeDoux JE (1992) Differential contribution of amygdala and hippocampus to cued and contextual fear conditioning. Behav Neurosci 106:274-285.

Piñon MC, Tuoc TC, Ashery-Padan R, Molnár Z, Stoykova A (2008) Altered molecular regionalization and normal thalamocortical connections in cortex-specific Pax6 knock-out mice. J Neurosci 28:8724-8734.

Quinn JC, Molinek M, Martynoga BS, Zaki PA, Faedo A, Bulfone A, Hevner RF, West JD, Price DJ (2007) Pax6 controls cerebral cortical cell number by regulating exit from the cell cycle and specifies cortical cell identity by a cell autonomous mechanism. Dev Biol 302:50-65.

Quirk GJ, Garcia R, González-Lima F (2006) Prefrontal mechanisms in extinction of conditioned fear. Biol Psychiatry 60:337-343.

Rakic P (1988) Specification of cerebral cortical areas. Science 241:170-176.

Raponi E, Agenes F, Delphin C, Assard N, Baudier J, Legraverend C, Deloulme JC (2007) S100B expression defines a state in which GFAPexpressing cells lose their neural stem cell potential and acquire a more mature developmental stage. Glia 55:165-177.

Roy K, Kuznicki K, Wu Q, Sun Z, Bock D, Schutz G, Vranich N, Monaghan AP (2004) The Tlx gene regulates the timing of neurogenesis in the cortex. J Neurosci 24:8333-8345.

Sakurai K, Osumi N (2008) The neurogenesis-controlling factor, Pax6, inhibits proliferation and promotes maturation in murine astrocytes. J Neurosci 28:4604-4612.

Schaeren-Wiemers N, André E, Kapfhammer JP, Becker-André M (1997) The expression pattern of the orphan nuclear receptor RORbeta in the developing and adult rat nervous system suggests a role in the processing of sensory information and in circadian rhythm. Eur J Neurosci 9:2687-2701.

Schieppati M, Musazzi M, Nardone A, Seveso G (1984) Interhemispheric transfer of voluntary motor commands in man. Electroencephalogr Clin Neurophysiol 57:441-447.

Schmahl W, Knoedlseder M, Favor J, Davidson D (1993) Defects of neuronal migration and the pathogenesis of cortical malformations are associated with Small eye (Sey) in the mouse, a point mutation at the Pax-6locus. Acta Neuropathol (Berl) 86:126-135.

Schuurmans C, Armant O, Nieto M, Stenman JM, Britz O, Klenin N, Brown C, Langevin LM, Seibt J, Tang H, Cunningham JM, Dyck R, Walsh C, Campbell K, Polleux F, Guillemot F (2004) Sequential phases of cortical specification involve Neurogenin-dependent and -independent pathways. EMBO J 23:2892-2902.

Shen Q, Wang Y, Dimos JT, Fasano CA, Phoenix TN, Lemischka IR, Ivanova NB, Stifani S, Morrisey EE, Temple S (2006) The timing of cortical neurogenesis is encoded within lineages of individual progenitor cells. Nat Neurosci 9:743-751.

Simpson TI, Price DJ (2002) Pax6; a pleiotropic player in development. Bioessays 24:1041-1051.

Sisodiya SM, Free SL, Williamson KA, Mitchell TN, Willis C, Stevens JM, Kendall BE, Shorvon SD, Hanson IM, Moore AT, van Heyningen V (2001) PAX6 haploinsufficiency causes cerebral malformation and olfactory dysfunction in humans. Nat Genet 28:214-216.

Stancak A, Hoechstetter K, Tintera J, Vrana J, Rachmanova R, Kralik J, Scherg M (2002) Source activity in the human secondary somatosensory cortex depends on the size of corpus callosum. Brain Res 936:47-57.

Stoykova A, Gruss P (1994) Roles of Pax-genes in developing and adult brain as suggested by expression patterns. J Neurosci 14:1395-1412.

Stoykova A, Fritsch R, Walther C, Gruss P (1996) Forebrain patterning defects in Small eye mutant mice. Development 122:3453-3465.

Stoykova A, Götz M, Gruss P, Price J (1997) Pax6-dependent regulation of adhesive patterning, R-cadherin expression and boundary formation in developing forebrain. Development 124:3765-3777.

Stoykova A, Treichel D, Hallonet M, Gruss P (2000) Pax6 modulates the dorsoventral patterning of the mammalian telencephalon. J Neurosci 20:8042-8050.

Stoykova A, Hatano O, Gruss P, Götz M (2003) Increase in reelin-positive cells in the marginal zone of Pax6 mutant mouse cortex. Cereb Cortex 13:560-571.

Takahashi T, Goto T, Miyama S, Nowakowski RS, Caviness VS Jr (1999) Sequence of neuron origin and neocortical laminar fate: relation to cell cycle of origin in the developing murine cerebral wall. J Neurosci 19:10357-10371.

Takebayashi H, Yoshida S, Sugimori M, Kosako H, Kominami R, Nakafuku M, Nabeshima Y (2000) Dynamic expression of basic helix-loop-helix Olig family members: implication of Olig2 in neuron and oligodendro- 
cyte differentiation and identification of a new member, Olig3. Mech Dev 99:143-148.

Tarabykin V, Stoykova A, Usman N, Gruss P (2001) Cortical upper layer neurons derive from the subventricular zone as indicated by Svetl gene expression. Development 128:1983-1993.

Thompson PJ, Mitchell TN, Free SL, Williamson KA, Hanson IM, van Heyningen V, Moore AT, Sisodiya SM (2004) Cognitive functioning in humans with mutations of the PAX6 gene. Neurology 62: $1216-1218$

Toresson H, Potter SS, Campbell K (2000) Genetic control of dorsal-ventral identity in the telencephalon: opposing roles for Pax6 and Gsh2. Development 127:4361-4371.

Tuoc TC, Stoykova A (2008a) Er81 is a downstream target of Pax6 in cortical progenitors. BMC Dev Biol 8:23.

Tuoc TC, Stoykova A (2008b) Trim11 modulates the function of neurogenic transcription factor Pax6 through ubiquitin-proteosome system. Genes Dev 22:1972-1986.
Walsh C, Cepko CL (1988) Clonally related cortical cells show several migration patterns. Science 241:1342-1345.

Walther C, Gruss P (1991) Pax-6, a murine paired box gene, is expressed in the developing CNS. Development 113:1435-1449.

Yun K, Potter S, Rubenstein JL (2001) Gsh2 and Pax6 play complementary roles in dorsoventral patterning of the mammalian telencephalon. Development 128:193-205.

Zhuo L, Theis M, Alvarez-Maya I, Brenner M, Willecke K, Messing A (2001) hGFAP-cre transgenic mice for manipulation of glial and neuronal function in vivo. Genesis 31:85-94.

Zhou Q, Wang S, Anderson DJ (2000) Identification of a novel family of oligodendrocyte lineage-specific basic helix-loop-helix transcription factors. Neuron 25:331-343.

Zimmer C, Tiveron MC, Bodmer R, Cremer H (2004) Dynamics of Cux2 expression suggests that an early pool of SVZ precursors is fated to become upper cortical layer neurons. Cereb Cortex 14:14081420 . 